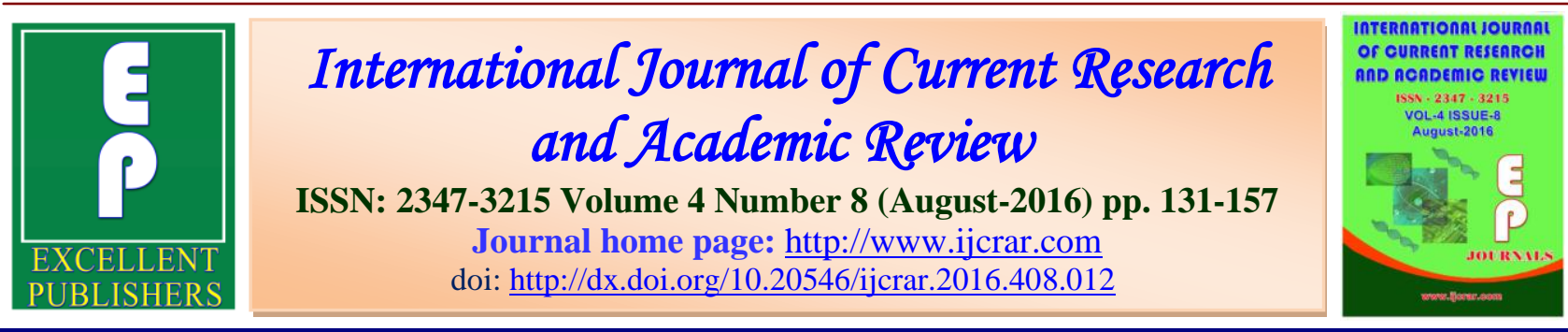

\title{
High Tibial Osteotomy: Long Term Follow-Up
}

\author{
Amit Agarwal $^{1 *}$, Imran Sajid ${ }^{2}$, Anubhav Agarwal $^{3}$ and Harish Chandra ${ }^{4}$ \\ ${ }^{1}$ Associate Professor, FH Medical College, Firozabad, India \\ ${ }^{2}$ Assistant Professor, F.H. Medical College, Agra, India \\ ${ }^{3}$ Chandra Orthopedic and Maternity Institute, Agra, India \\ ${ }^{4}$ Professor \& Head, S.N. Medical College, Agra, India \\ *Corresponding author
}

\section{KEYWORDS \\ Arthritis, high tibial osteotomy, long term follow up}

\section{A B S T R A C T}

Pain in the knee joint is one of the most complaints found among the patient attending outdoor. Its existence dates since the adoption of erect posture by mankind. Arthritis may cause mild to moderate pain while to pain at rest joint stiffness varus or valgus deformity. These may withheld a person from his job by preventing him from sitting cross-legged, squat or climb the stairs or walk distances etc. Role of high tibial osteotomy has been studied for prompt relief of symptoms and thus make the patient able to lead a longer independent life. 400 cases were operated during a time period of 11 years from 2005 to 2016. Majority of them were sedentary workers. Majority of the patients have duration of complaints between 1-2 years. The Pain was mostly located on the medial side $\&$ the pre operative feeling of instability was absent in majority of cases. The Pre operative range of movement was between 90-120 degrees in 68\% of cases. Apart from progressive varus deformity in small gropup of patients and mild pain in the knee joint most patients were benefited by this procedure. 200 cases were operated by wedge osteotomy at the level of tibialtuberosity, 125 below the level and 75 by dome osteotomy. Results were evaluated on the basis of Bailey knee assessment scale. All patients were benefited by surgery as regards the relief of pain. Very old and obese patients showed poor results after surgery due to their inability to do required physiotherapy. Patients having symptoms for shorter duration of showing early evidence of radiological changes responded to surgery better as compared to those having advanced changes. Patient with $1-10^{\circ}$ of postoperative valgus in tibio-femoral alignment obtained maximum pain relief and good range of motion. Over correction and failure to achieve valgus showed poor results. $75 \%$ of patients showed good results, $20 \%$ fair \& $5 \%$ poor. According to Bailey Knee assessment scale $75 \%$ of patients showed good results, $20 \%$ fair \& $5 \%$ poor. Better resutls were obtained by dome osteotomy as comapred to wedge osteotomy regarding relief of pain, post oerpative range of knee motion, and abilities to walk distances, climb the stairs, squat or sit crosslegged. Osteotomy of fibula in dome osteotomy required special care to avoid complications like pain at fibular osteotomy site and weakness of dorsiflexion of foot. Thus high tibial osteotomy is a boon for early osteoarthritis of knee with unicompartmental involvement and to some extent with moderate to advance osteoarthritis in developing countries as clearly indicated in our study. 


\section{Introduction}

Arthritis ${ }^{1}$ of the knee becomes one of the front liners among the causes of man's disablement. Arthritis may cause mild to moderate pain while to pain at rest, joint stiffness and varus or valgus deformity. These may withheld a person from his job by preventing him from sitting crosslegged, squat or climb the stairs or walk distances etc. Anti inflammatory analgesics drugs, physiotherapy and change in life style comprise essential part of conservative treatment. Various surgical procedures like synovectomy, patelectomy, joint debridement, arthrodesis, arthroscopic surgery and osteotomies and joint replacement have been described. Role of osteotomy have been studied for prompt relief of symptoms and thus make the patient able to lead a longer independent life.

To assess the advantages of high tibial osteotomy by various methods in patients with different grades of osteoarthritis of knee and its long term follow up in those patients.

\section{Material and Methods}

The study comprises of 400 patients of osteoarthritis knee which have been operated during the time period of 2005 to 2016 and their follow up has been evaluated. Apart from progressive varus deformity in small group of patients as well as mild pain in knee joint most of the patients were benefited by this procedure. The procedure was carried out in 3 institutes i.e. 1- S.N. Medical College, Agra, 2- Chandra Orthopedic and Maternity Research Institute \& 3F.H. Medical College \& Research Institute.

Each of the patient was clinically evaluated against a prescribed chart, which is as follows -

\section{Investigation}

Blood, Urine,

X-ray - A.P. View, in weight bearing, Lateral view and Tangential view.

Weight bearing X-rays were done in all cases to assess severity of varus and valgus deformities. Patients with mild to moderate pain with no evidence of unicompartmental disease were treated conservatively by anti-inflammatory analgesics, quadriceps strengthening exercises, foamentation and intraarticular hydrocortisone injections at weekly intervals.

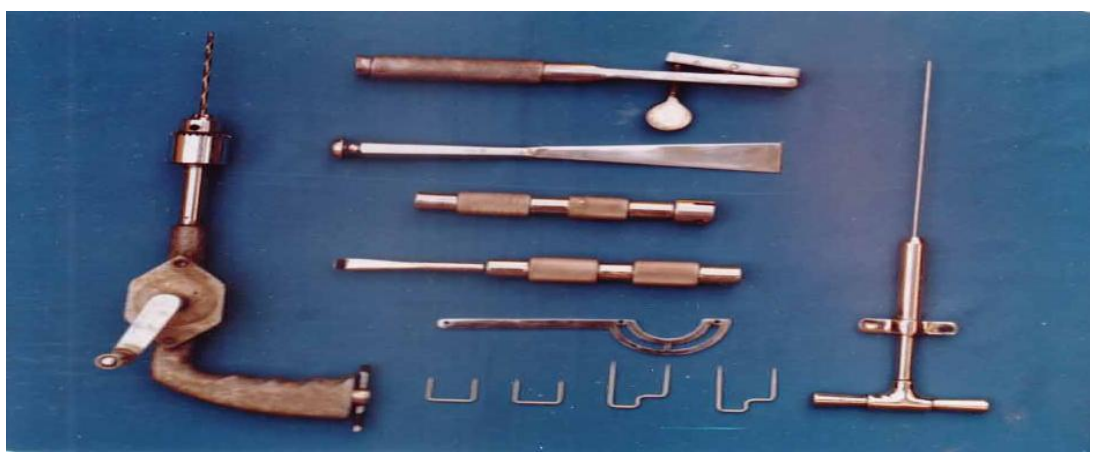

Fig.-11: Essential instruments and implants : The drill, Staple holder, Osteotome, Staple Impactor and extractor, Curved guide for drill, Plain \& Stepped staples and T- handle with guide wire. 


\section{High Tibial Osteotomy}

Patients revealing diminished joint space in medial or lateral compartment on weight bearing X-ray films were subjected to high tibial osteotomy. Preoperatively amount of valgus or varus deformity was measured by drawing tibial and femoral axes. Closing Wedge osteotomy was done in 240 cases and opening Wedge osteotomy with insertion of graft in 40 cases. Dome osteotomy was done in 120 cases (Dugdale et al., 1992).

\section{Wedge Osteotomy}

Wedge osteotomy was done by two methods :
Osteotomy done just at the level of tibial tuberosity (160 cases) (Coventry et al., 1973).

Osteotomy done below the level of tibial tuberosity (80 cases)

Patient anaesthetised and Esmarch's bandage applied to the limb. Lateral longitudinal incision given. Head of fibula osteotomised obliquely. Upper tibio femoral syndesmosis seperated. Wedge of desired size removed with base being laterally for correction of varus deformity $1 \mathrm{~mm}$ of base in taken for each 1 degree of correction (Myrnerts Rune, 1980).

\section{Wedge Osteotomy}

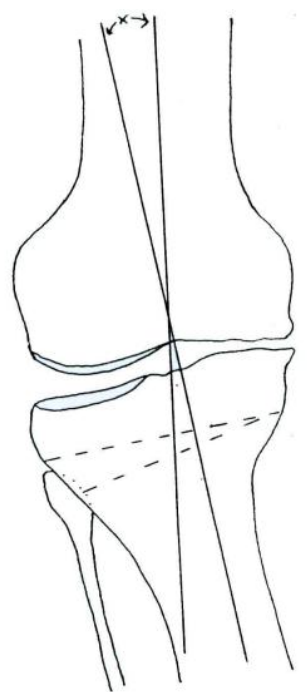

Size of wedge ' $x$ ' $m m+5 m m$ for normal valgus

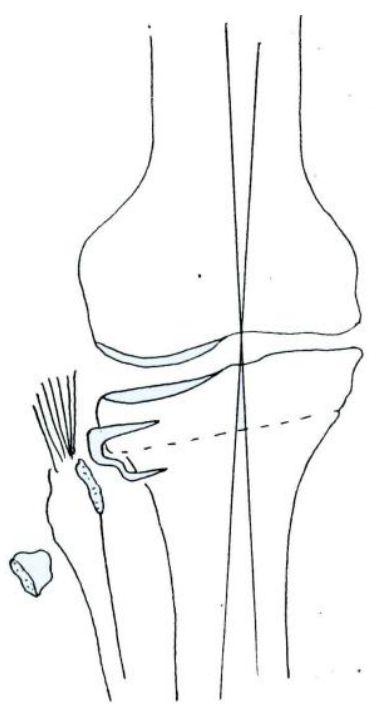

Head of the fibula osteotomised obliquely.

- Upper tibiofibular syndesmosis separated.

- Fragments fixed with staples after wedge resertinn 
Size of Wedge : varus in degrees + $5-7^{\circ}$ for normal valgus in $\mathrm{mm}$

Upper level of osteotomy is kept $2 \mathrm{~cm}$ away from tibial articular surface which is judged by passing a guide wire through the joint. After removal of the wedge, correction done and 1 or 2

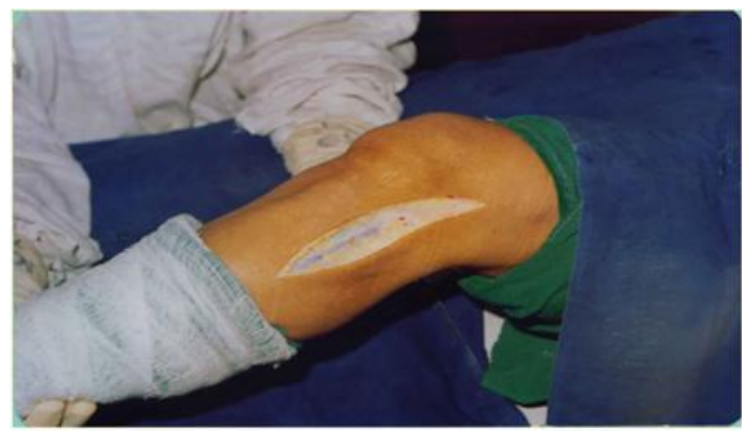

Showing lateral longitudinal incision for wedge osteotomy the knee is held in slight flexion

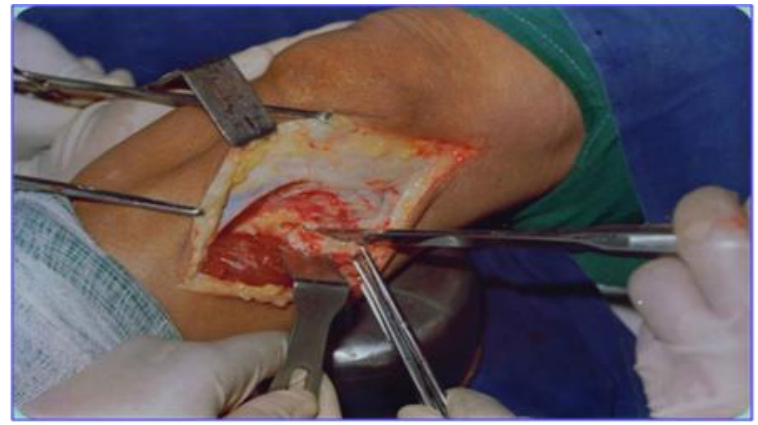

Showing the head of fibula being osteotomized obliquely

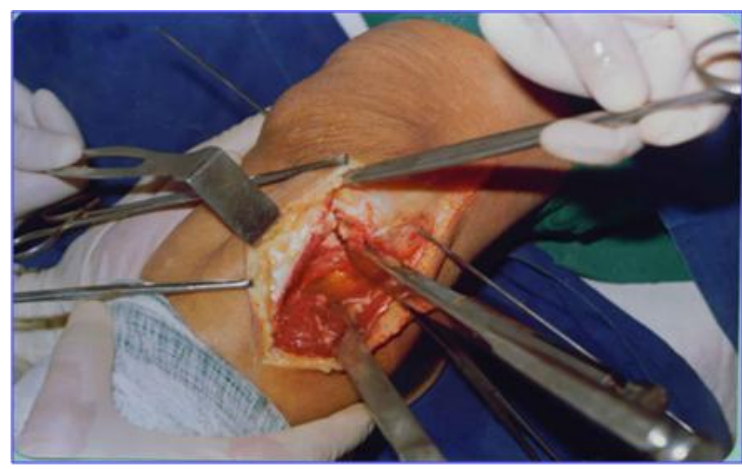

Showing the tibia being osteotomized from the lateral side about $2 \mathrm{~cm}$ below the guide wire stepped staples placed in to hold the fragments.

The opening wedge osteotomy is done from medial side and a graft from iliac crest is inserted into the wedge. No staple is applied and cylinder plaster given.

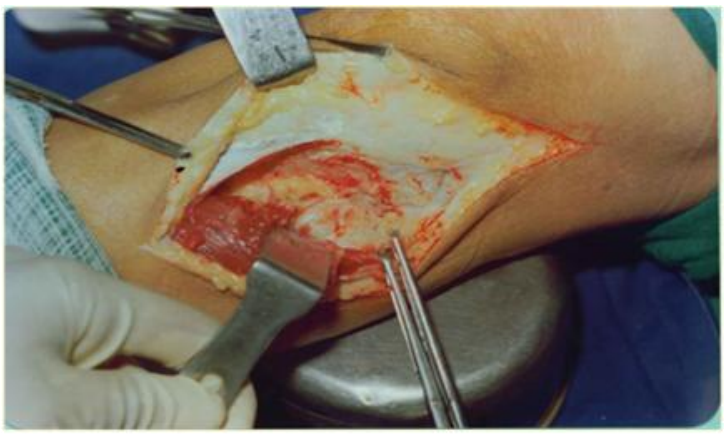

Showing the exposure of head of fibula
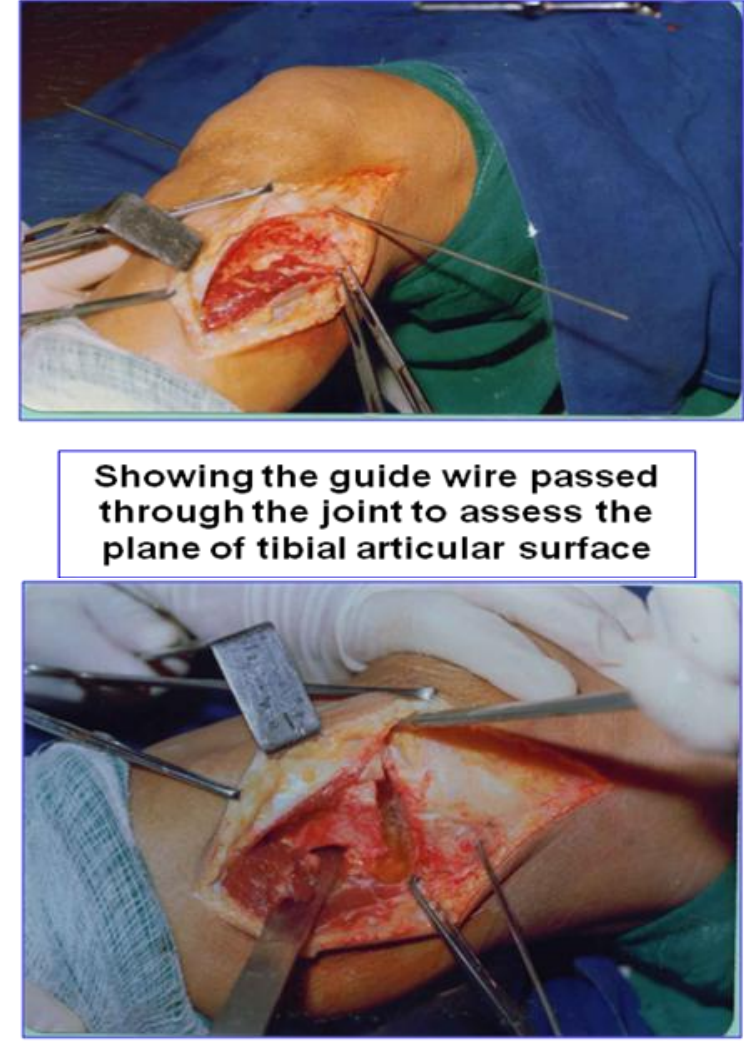

Showing the wedge resected from the lateral side of tibia 

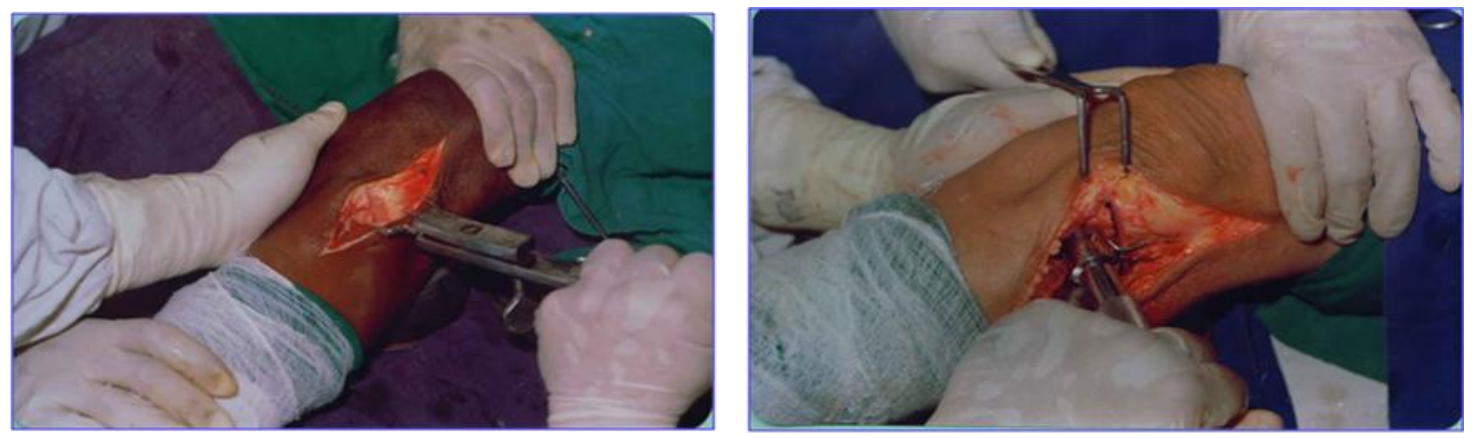

Showing initial insertion of stepped staple after achieving correction

Showing staple being impacted

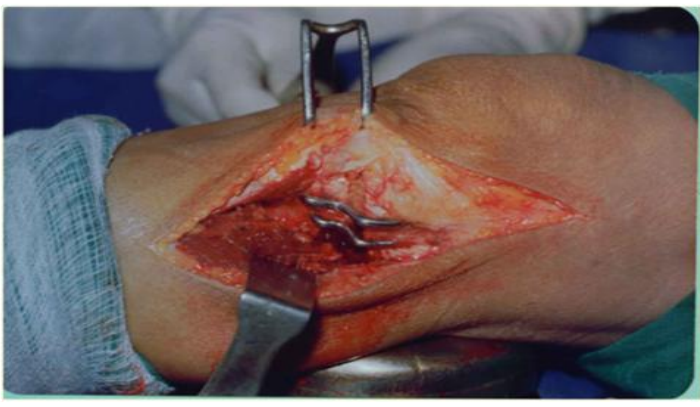

Showing staples in position

\section{Dome Osteotomy}

First fibula Is osteotomised through a small lateral incision in middle third of leg and cut ends of fibula displaced after osteotomy. Another anterior midline incision given and patellar tendon exposed upto tibial tuberosity. A guide wire passed through joint to guide the plane of tibial articular surface. Then a curved guide passed behind the patellar tendon to guide the curve of osteotomy. Multiple drill holds made through this guide into the bone. The guide Is removed and bone is osteotomised Along these drill boles. After the bone is cut in shape of done, distal fragment is rotated into the concavity of proximal fragment till desired correction is achieved. Post operative valgus position is judged by the guide wire into the joint.
THE DOME OSTEOTOMY
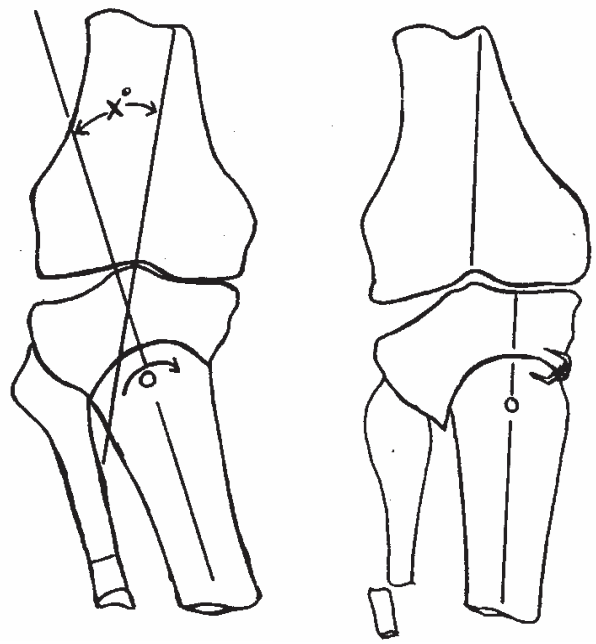

- Curved osteotomy of tibia done above tibial tuberosity

- Fibula osteotomised in mid shaft \& fragments displacec

- Distal tibia rotated for correction of deformity.

- Fragments fixed bv staples. 
Fragments are held In position by 1-2 staples (Sundaram et al., 1986; Benjamin, 1969).

\section{Post operative regimen}

Suction drainage for 8 hours was used routinely in every case and cylinder plaster was given. Quadriceps exercises were started within plaster the day of surgery. Partial weight bearing was started after 4 weeks with the help of

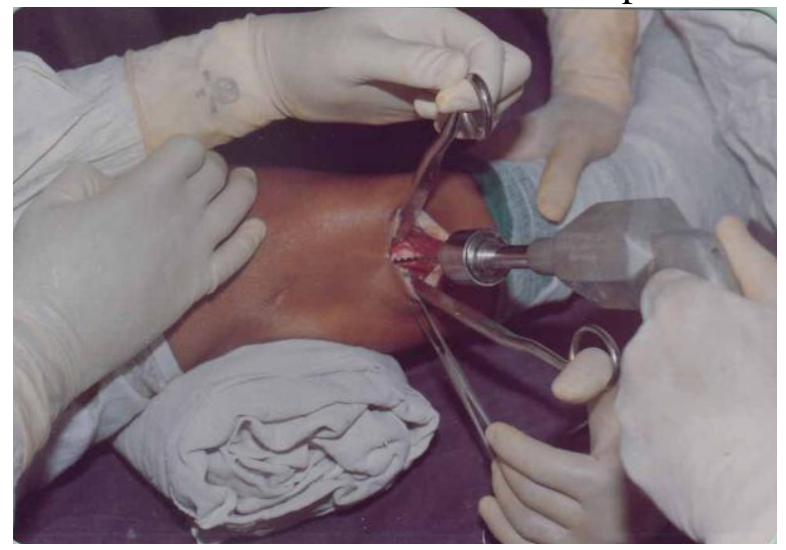

Fig.-1: Showing drilling of fibula after exposing it from lateral side in middle third of shaft

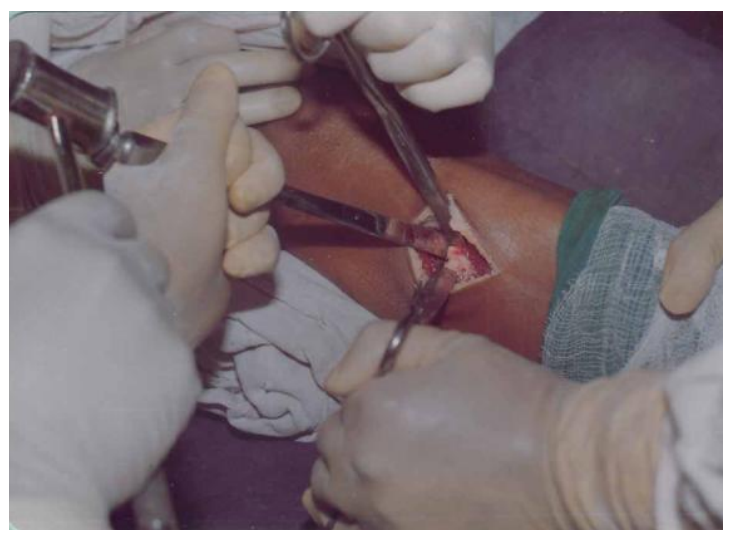

Fig.-2: Showing the fibula being osteotomised crtuches. Plaster was removed after 8 weeks and check X-rays were taken. Range of motion exercises and full weight bearing was started after evidence of union. Average follow-up period was around 5 years range 2-12 years. Out of 400 operated cases there were 250 females and 150 males. Average age was 55.2 years range $35-70$ years.

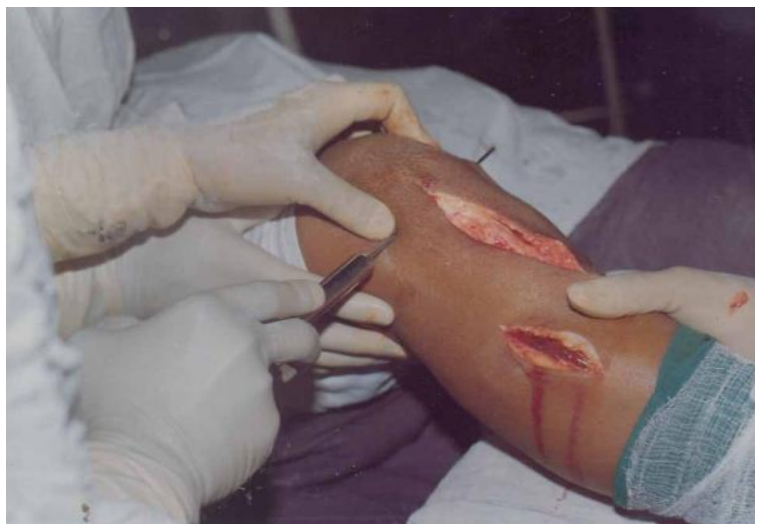

Fig.-3: Showing guide wire being passed through I the joint to-assess the plane of tibial articular surface.

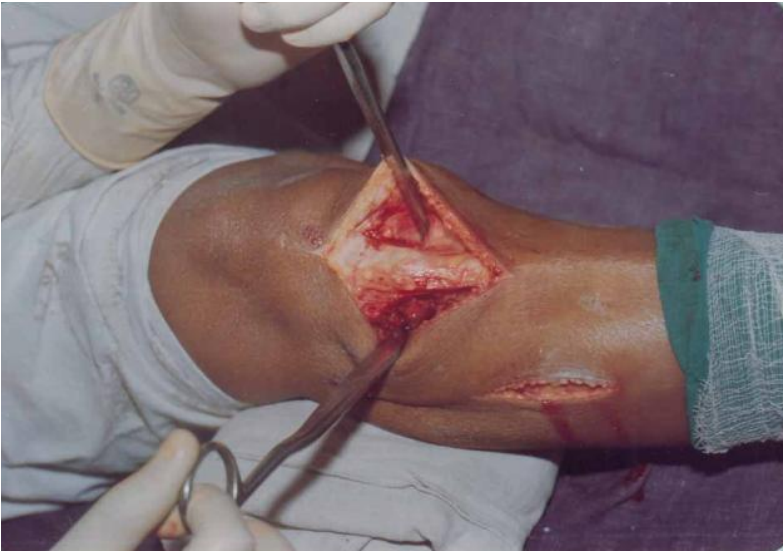

Fig.-4: Showing exposure of patellar tendon, upto tibial tubrosity 


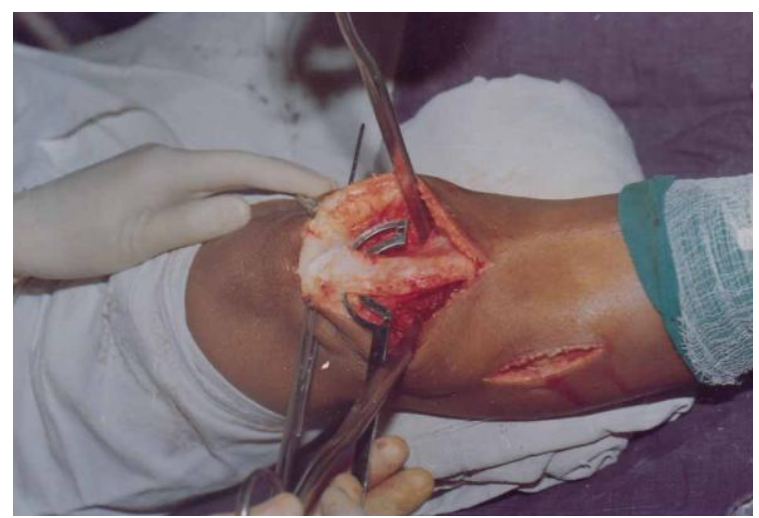

Fig.-5: Showing placement of curved guide for drill to drill the tibia in shape of curve.

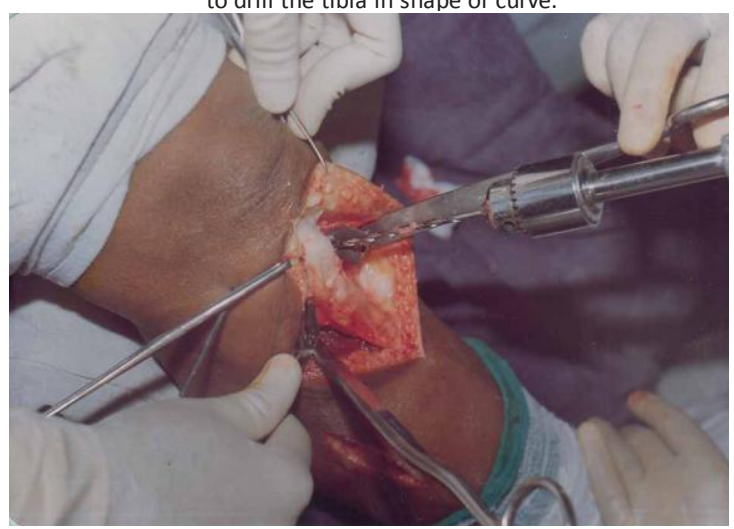

Fig.-6: Showing the tibia being drilled through the curved guide.

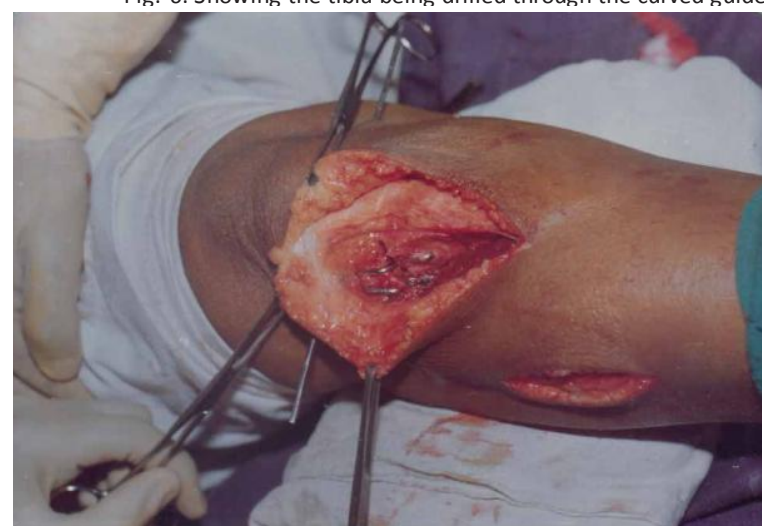

Fig.-9: Showing final position of staples

\section{Results and Discussion}

In our series highest number of cases suffering from osteoarthritis of knee were in sixth decade and lowest between fourth and fifth decades (Table-1). Majority of cases were female (Table-2). Most of the patients were sedentry workers (Table-3) and the duration of complaints was between 1 to 2

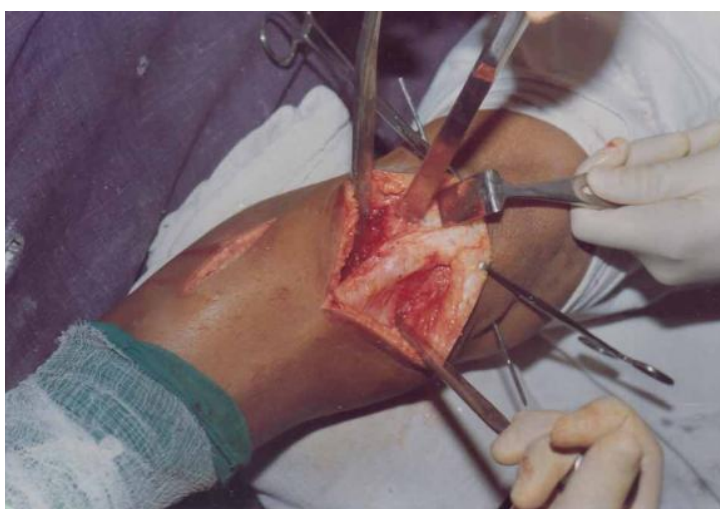

Fig.-7: Showing the tibia being osteotomised along

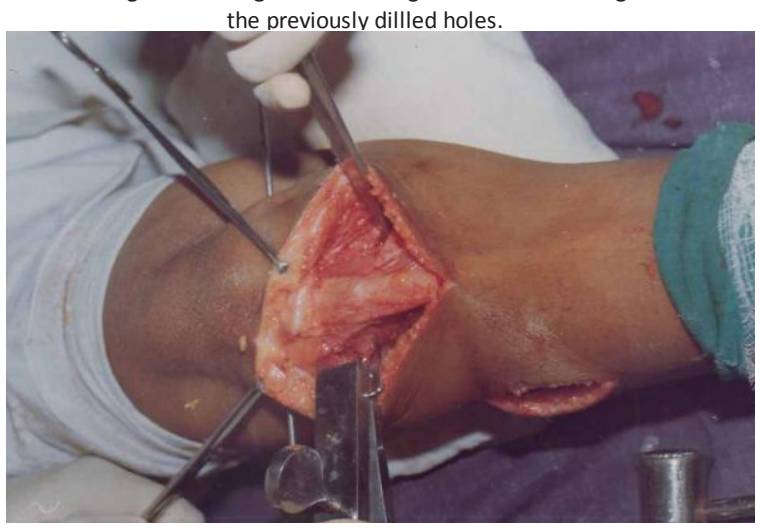

Fig.-8: Showing the stepped staple being insertec into the fragments after correction of deformity years (Table-4). It was seen majority cases pain was very sever and was localized on the medial side of knee (Table-5 \& 6). In maximum number of patients instability was absent (Table-7) and history of previous trauma was absent in majority of cases (Table-8). Patients were assessed according to the distance walked, climbing stairs their ability to sit on chair, squating, sitting cross legged and use of aids (Table-9).

It was also noticed that majority of patients have movement of knee between $90-120^{\circ}$ and preoperative flexion deformity was between $0-5^{\circ}$ in majority of the cases (Table$10 \& 11)$.

Management of osteoarthritis of the knee joint has ever been a problem. Clinically the symptoms very from mild pain on walking or climbing stairs to moderate or severe pain during day to day activity or even at rest. 
Also there may develop flexion deformity of varus or valgus deformity at knee.

Pathological changes that take place in an osteoarthritic knee include osteophytes formation along the margins of tibial and femoral condylar articualr surfaces, and the patellar articular surface, degeneration of articular cartilage causing diminution of joint space in medial or lateral or both the compartments of the joint, synovial thickening, degeneration of menisci, presence of loose bodies inside the joint, sclerosis and cyst formation in the subchondral bone. The weakness of vastus lateralis also plays role in making the line of weight bearing to shift medially and thus causing more stress on medial compartment of the knee joint. This further leads to early degenerative changes in medial compartment and varus deformity of knee.

Mode of treatment varies from patient to patient depending upon the underlying pathological changes due to osteoarthritis. The management has evolved from conservative measures in form of foamentation, anti-inflammatory analgesic drugs, excercises, intraarticular hydrocortisone injection (Sarkin, 1972) and procaine needling, to operative measures like Synovectomy (Steindler, 1955). Patellectomy (Coventry, 1987; Ackroya, 1977; Berkeiser, 1939), Joint Debridment (MacIntosh et al., 1977; David, 1977), Femoral and tibial osteotomies about the knee, Arthoscopic surgery and partial and total knee replacement surgery (van Raaij et al., 2009).

400 cases of osteoarthritis knee with unicompartmental involvement were operated during a time period of 12 years (2004-2016) and results were evaluated. The procedure undertaken was 1 . wedge osteotomy at the level of tibail tuberosity, 2 . wedge osteotomy below the level of tibial tuberosity and 3. dome osteotomy. It was observed cases above 65 years of age could obtain only fair results in the series Majority of the cases with good results were below 65 years of age. The possible reason was inability to do physiotherapy. Obese pateints were found to wrong selection for operation. In our series local of more severe pain was found to be medial $(71.6 \%)$ cases, $16.6 \%$ anterior, $6.6 \%$ lateral and $5 \%$ had posterior. This clinical observation along radiological examination leads to conclusion that medial compartment is first and most common to be involved. Next commonly there is involvement of patellofemoral joint (Insall et al., 1984; Benjamin, 1969; Jakob et al., 2004).

The duration of preoperative complaints has greatly influenced the outcome of surgery. The best results were obtained in patients with a history of illness for less than one year. In this series $69.2 \%$ of cases having complaints for less than 1 year showed good results while only $44.1 \%$ showed good results with duration of complaints for over one year.

It may be argued that some of the patients with lesser duration of preoperative complaints could have done well, anyhow, if they were treated with conservative measures. This could well be so, but does not take into account the long period of pain and disabilities and the loss of time from work that would have been involved. It may be recommended that patients not responding to conservative measures within 6-8 months or having relapsed within a year should be subjected to surgery.

Improvement in pain was observed in all patients and no case had severe pain persisting postoperatively. Preoperative moderate to severe pain was present in $91.6 \%$ cases while there were only $5 \%$ cases with mild pain after operation. 
Int.J.Curr.Res.Aca.Rev.2016; 4(8): $x x-x x$

Function was also greatly improved in patients after operation. All patients could walk after surgery. $50 \%$ of the patients could do outdoor activities as compared to $10 \%$ preoperatively. Only 12 cases were using stick for walking postoperatively while 100 were using it earlier. All patients were able to sit comfortably in chair without any difficulty while $18.3 \%$ had difficulty previously.

Overall there were $61.6 \%$ cases who could climb the stairs preoperatively. Postoperative improvement occurred in $91.6 \%$ cases. Preoperatively $26.6 \%$ of patients were unable to sit cross legged. They reduced to $13.3 \%$ after operation. One third of total cases could sit cross legged perfectly normally after operation as compared to $18.3 \%$ preoperatively. Squatting abilities of patients also improved. Over $80 \%$ could squat after operation compared to $36.6 \%$ preoperatively.

Instability or insecurity while walking was complained by $18.3 \%$ cases preoperatively reduced to $13.3 \%$ cases postoperatively.
It was found that most of the patients $(66.6 \%)$ were able to sit on chair (flex upto $\left.90^{\circ}\right)$ within one month and a few (13.3\%) could flex upto $120^{\circ}$. After 6 months of removal of plaster $86.6 \%$ of cases could flex beyond $90 \%$ out of them. $26.6 \%$ had flexion beyond $120^{\circ}$ and $60 \%$ between $90-120^{\circ}$.

The results of high tibial osteotomy were very encouraging. In our series at osteotomy, attempt was made to correct flexion and varus or valgus deformities at knee due to osteoarthritis. Previously 21 cases $(35 \%)$ had flexion deformity at knee, which was corrected in majority of cases.

Tibiofemoral alignment which required correction, was varus in $50 \%, 0^{\circ}$ in 50 cases and more than $10^{\circ}$ valgus in 10 cases. At surgery $5-7^{\circ}$ of valgus was aimed.

No attempt at over correction was made. Postoperatively $60 \%$ had valgus of $1-5^{\circ}$ and $28.3 \%$ between $6-10^{\circ}$. $5 \%$ cases had valgus more than $10^{\circ}$ (Table-12).

Table.1 Showing the age distribution

\begin{tabular}{|c|c|c|}
\hline Age group (yrs) & No. of cases operated & Percentage \\
\hline $18-30$ & - & - \\
\hline $31-40$ & 13 & 3.3 \\
\hline $41-50$ & 14 & 3.3 \\
\hline $51-60$ & 313 & 78.3 \\
\hline Above 60 & 60 & 15 \\
\hline
\end{tabular}

Table.2

\begin{tabular}{|c|c|c|}
\hline Sex & No. of cases operated & Percentage \\
\hline Male & 150 & 37.5 \\
\hline Female & 250 & 55.5 \\
\hline
\end{tabular}


Int.J.Curr.Res.Aca.Rev.2016; 4(8): $x x-x x$

Table.3 Showing distribution of quality of life

\begin{tabular}{|l|c|c|}
\hline \multicolumn{1}{|c|}{ Quality of life } & No. of cases operated & Percentage \\
\hline Heavy manual workers & 75 & 18.3 \\
\hline Sedentary workers & 166 & 41.7 \\
\hline Retired life & 113 & 28.3 \\
\hline Unable to do any work & 46 & 11.6 \\
\hline
\end{tabular}

Table.4 Showing duration of complaints

\begin{tabular}{|l|c|c|}
\hline \multicolumn{1}{|c|}{ Duration } & No. of cases operated & Percentage \\
\hline Less than 6 months & 61 & 15.0 \\
\hline 6 months - 1 year & 113 & 28.3 \\
\hline 1 year - 2 years & 153 & 38.3 \\
\hline More than 2 years & 73 & 18.3 \\
\hline
\end{tabular}

Table.5 Showing severity of preoperative pain

\begin{tabular}{|l|c|c|}
\hline Severity of Pre-op. pain & No. of cases operated & Percentage \\
\hline Severe & 226 & 56.6 \\
\hline Moderate & 140 & 35.3 \\
\hline Mild & 34 & 8.3 \\
\hline None & 0 & - \\
\hline
\end{tabular}

Table.6 Showing location of most severe pain

\begin{tabular}{|l|c|c|}
\hline Location & No. of cases operated & Percentage \\
\hline Medial & 286 & 71.6 \\
\hline Lateral & 26 & 6.6 \\
\hline Anterior & 68 & 16.6 \\
\hline Posterior & 20 & 5.0 \\
\hline
\end{tabular}


Int.J.Curr.Res.Aca.Rev.2016; 4(8): $x x-x x$

Table.7 Showing preoperative feeling of instability/insecurity while walking

\begin{tabular}{|l|c|c|}
\hline Insatability/ Insecurity & No. of cases operated & Percentage \\
\hline Present & 73 & 18.3 \\
\hline Absent & 327 & 81.7 \\
\hline
\end{tabular}

Table.8 Showing history of previous trauma

\begin{tabular}{|l|c|c|}
\hline History of previous trauma & No. of cases operated & Percentage \\
\hline Present & 26 & 6.6 \\
\hline Absent & 374 & 93.3 \\
\hline
\end{tabular}

Table.9 Showing preoperative abilities of patient

\begin{tabular}{|c|c|}
\hline Preoperative abilities & Percentage \\
\hline $\begin{array}{l}\text { Distance walked } \\
\text { - Unlimited } \\
\text { - Limited } \\
\text { - Indoors only } \\
\text { - Unable }\end{array}$ & $\begin{array}{c}12 \\
35 \\
48 \\
5\end{array}$ \\
\hline $\begin{array}{l}\text { Climbing stairs } \\
\text { - Easily } \\
\text { - With difficulty } \\
\text { - Unable } \\
\end{array}$ & $\begin{array}{l}20 \\
62 \\
18\end{array}$ \\
\hline $\begin{array}{l}\text { Sitting in Chair } \\
\text { - Easily } \\
\text { - With difficulty } \\
\text { - Unable }\end{array}$ & $\begin{array}{c}92 \\
8 \\
-\end{array}$ \\
\hline $\begin{array}{l}\text { Squating } \\
\text { - Easily } \\
\text { - With difficulty } \\
\text { - Unable }\end{array}$ & $\begin{array}{c}7 \\
30 \\
63\end{array}$ \\
\hline $\begin{array}{l}\text { Sitting Cross legged } \\
\text { - Easily } \\
\text { - With difficulty } \\
\text { - Unable }\end{array}$ & $\begin{array}{l}19 \\
55 \\
26\end{array}$ \\
\hline $\begin{array}{cl}\text { Use of Aids } \\
\text { - } & \text { No aids } \\
\text { - } & \text { Stick } \\
\text { - } & \text { Crutches } \\
\end{array}$ & $\begin{array}{c}70 \\
30 \\
- \\
\end{array}$ \\
\hline
\end{tabular}


Int.J.Curr.Res.Aca.Rev.2016; 4(8): $x x-x x$

Table.10 Range of preoperative movement

\begin{tabular}{|l|c|c|}
\hline & No. of cases operated & Percentage \\
\hline $0-60^{\circ}$ & - & - \\
\hline $60-90^{\circ}$ & 26 & 6.6 \\
\hline $90-120^{\circ}$ & 273 & 68.3 \\
\hline More than $120^{\circ}$ & 101 & 25.0 \\
\hline
\end{tabular}

Table.11 Preoperative flexion deformity

\begin{tabular}{|l|c|c|}
\hline Flexion deformity & No. of cases operated & Percentage \\
\hline $0-5^{\circ}$ & 132 & 20 \\
\hline $6-10^{\circ}$ & 80 & 11.6 \\
\hline $11-15^{\circ}$ & 46 & 3.3 \\
\hline More than $15^{\circ}$ & - & - \\
\hline
\end{tabular}

Table.12 Showing tibifemoral alignment on standing

\begin{tabular}{|c|c|c|}
\hline Tibiofemoral alignment & No. of cases operated & Percentage \\
\hline $0^{\circ}$ & 66 & 16.6 \\
\hline Valgus & 120 & \\
$\bullet$ & 0 & 30 \\
$\bullet \quad 6-10^{\circ}$ & 13 & - \\
$\bullet>10^{\circ}$ & & 3.3 \\
\hline Varus & 93 & \\
$\bullet \quad 1-5^{\circ}$ & 60 & 23.3 \\
$\bullet \quad 6-10^{\circ}$ & 46 & 15.0 \\
$\bullet>10^{\circ}$ & & 11.6 \\
\hline
\end{tabular}

Table.13 Numebr of cases

\begin{tabular}{|c|c|c|}
\hline $\begin{array}{c}\text { HTO at the level of } \\
\text { tibial tuberosity }\end{array}$ & $\begin{array}{c}\text { HTO below the level of } \\
\text { tibial tuberosity }\end{array}$ & $\begin{array}{c}\text { Dome } \\
\text { Osteotomy }\end{array}$ \\
\hline 200 & 125 & 75 \\
\hline
\end{tabular}

Assessment of results was done on the basis of following criteria. At every follow up points scored by the patient were noted and results were graded accordingly (Table-14). 
Int.J.Curr.Res.Aca.Rev.2016; 4(8): $x x-x x$

Table.14 Showing criteria on which results were assessed and graded bailey knee assessment scale

\begin{tabular}{|l|c|c|}
\hline Criteria & Points scored & Total \\
\hline Pain & 0 & \\
Severe & 6 & 15 \\
Moderate & 12 & \\
Mild & 15 & \\
None & 5 & \\
\hline Function & 5 & 20 \\
Walking distances & 3 & \\
Walking aids & 2 & \\
Stair climbing & 5 & \\
Resting in chair & & \\
Giving way & & \\
\hline Movements & 3 & 5 \\
1 point for each $12^{\circ}\left(\right.$ Max. $\left.120^{\circ}\right)$ & 2 & \\
\hline Deformity & & 50 \\
No fixed flexion or lag & & \\
Varus/valgus angle & & \\
\hline Total & & \\
\hline
\end{tabular}

GRADING OF RESUTLS

GOOD

FAIR

POOR
POINTS SCORED

$35-40$

30-34

$<30$

Table.15 SHOWING LENGTH OF FOLLOW UP

\begin{tabular}{|l|c|c|}
\hline Period (years) & No. of cases operated & Percentage \\
\hline$<1$ year & 72 & 18.0 \\
\hline $1-2$ & 120 & 30.0 \\
\hline $2-4$ & 64 & 16.0 \\
\hline $4-6$ & 72 & 18.0 \\
\hline $6-8$ & 40 & 10.0 \\
\hline $8-10$ & 32 & 8.0 \\
\hline
\end{tabular}


Int.J.Curr.Res.Aca.Rev.2016; 4(8): $x x-x x$

Table.16 Showing comparative results of HTO at the level of TT, HTO below the level of TT and dome osteotomy

\begin{tabular}{|c|c|c|c|c|c|c|c|}
\hline \multirow[t]{2}{*}{ Parameters (postoperative) } & \multicolumn{2}{|c|}{ HTO at the level of TT } & \multicolumn{2}{|c|}{ HTO below the level of TT } & \multicolumn{2}{|c|}{ Dome osteotomy } & \multirow[t]{2}{*}{$P$ value } \\
\hline & No. of cases & $\%$ & No. of cases & $\%$ & No. of cases & $\%$ & \\
\hline \multicolumn{8}{|l|}{ Pain } \\
\hline - None & 76 & 38.4 & 40 & 32.0 & 32 & 43.7 & $>0.8$ \\
\hline - Mild & 84 & 42.3 & 50 & 40.0 & 32 & 43.7 & $>0.3$ \\
\hline - $\quad$ Moderate & 38 & 19.2 & 32 & 26.0 & 9 & 12.5 & 0 \\
\hline - Severe & - & - & . & - & & - & \\
\hline \multicolumn{8}{|l|}{ Range of motion } \\
\hline - $120^{\circ}$ & 69 & 34.6 & 40 & 32.2 & 32 & 43.7 & $>0.9$ \\
\hline - $90-120^{\circ}$ & 115 & 57.6 & 68 & 54.6 & 42 & 56.3 & - \\
\hline - $60-90^{\circ}$ & 15 & 7.8 & 25 & 20.0 & 28 & - & - \\
\hline - $\quad<60^{\circ}$ & - & - & - & - & - & - & - \\
\hline \multicolumn{8}{|l|}{ Function } \\
\hline \multicolumn{8}{|l|}{ Distance walked } \\
\hline - Limited & 107 & 53.9 & 63 & 50.8 & 37 & 50.0 & $>0.01$ \\
\hline - Indoors only & 30 & 15.3 & 26 & 20.8 & 9 & 12.5 & - \\
\hline - Unable & - & - & - & - & . & - & - \\
\hline \multicolumn{8}{|l|}{ Climbing stairs } \\
\hline - Easily & 153 & 76.9 & 90 & 72.0 & 60 & 81.3 & $<0.1$ \\
\hline - With difficulty & 38 & 19.2 & 30 & 24.0 & 14 & 18.7 & $>0.5$ \\
\hline - Unable & 8 & 3.8 & 10 & 8.2 & - & - & $<0.02$ \\
\hline \multicolumn{8}{|l|}{ Squating } \\
\hline - $\quad$ Easily & 107 & 53.9 & 58 & 46.8 & 37 & 50.0 & $<0.01$ \\
\hline - With difficulty & 69 & 34.6 & 47 & 38.0 & 32 & 43.7 & $>0.10$ \\
\hline - Unable & 22 & 11.4 & 19 & 15.2 & 4 & 6.3 & $<0.05$ \\
\hline \multicolumn{8}{|l|}{ Sitting cross legged } \\
\hline - With difficulty & 69 & 34.6 & 47 & 38.0 & 37 & 50.0 & $<0.50$ \\
\hline - Unable & 15 & 7.8 & 15 & 12.0 & - & - & $<0.02$ \\
\hline
\end{tabular}

Thus in our table painlees kneen after dome osteotomy was present in $43.7 \%$ as compared to $38.4 \%$ in cases of wedge osteotomy (Table-16).

Table.17 Showing incidence of complications

\begin{tabular}{|l|c|c|}
\hline Complications & No. of operated cases & Percentage \\
\hline Superficial infection & 20 & 5.0 \\
\hline Deep infection & - & - \\
\hline Non-union of osteotomy & - & - \\
\hline Weakness of dorsiflexion of foot & 12 & 3.0 \\
\hline Pain at site of fibular osteotomy & 33 & 8.3 \\
\hline Fracture into the joint & 8 & 2.0 \\
\hline
\end{tabular}




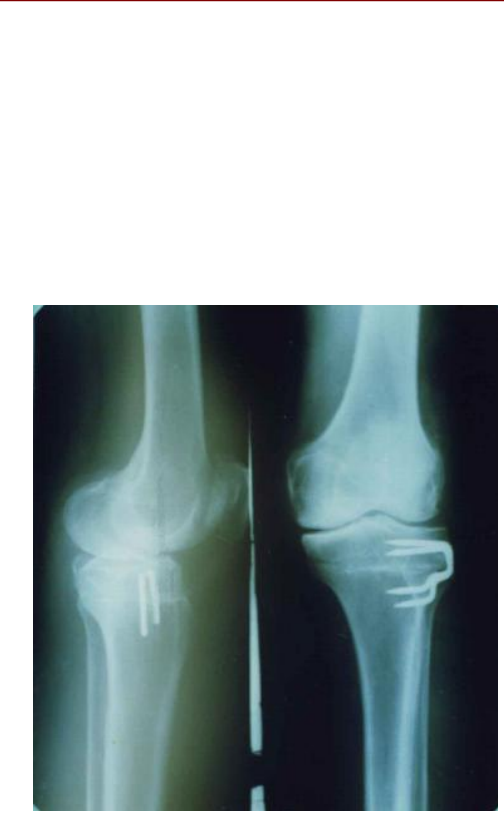

Immediate post-op. X-ray after wedge osteotomy tibio femoral alignment has been made valaus $5^{\circ}$

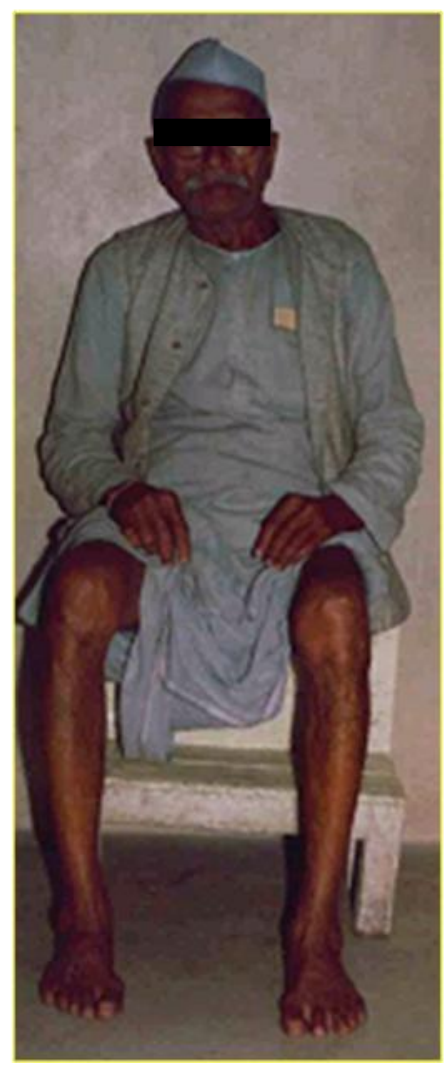

CASE NO. 1

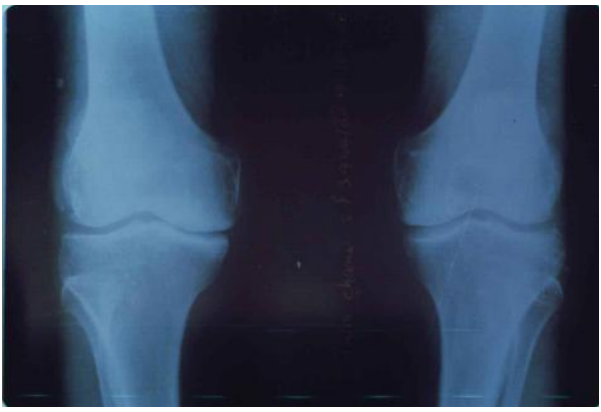

Preop. X-ray showing diminished joint space in medial compartment and varus $7^{\circ}$ on left side
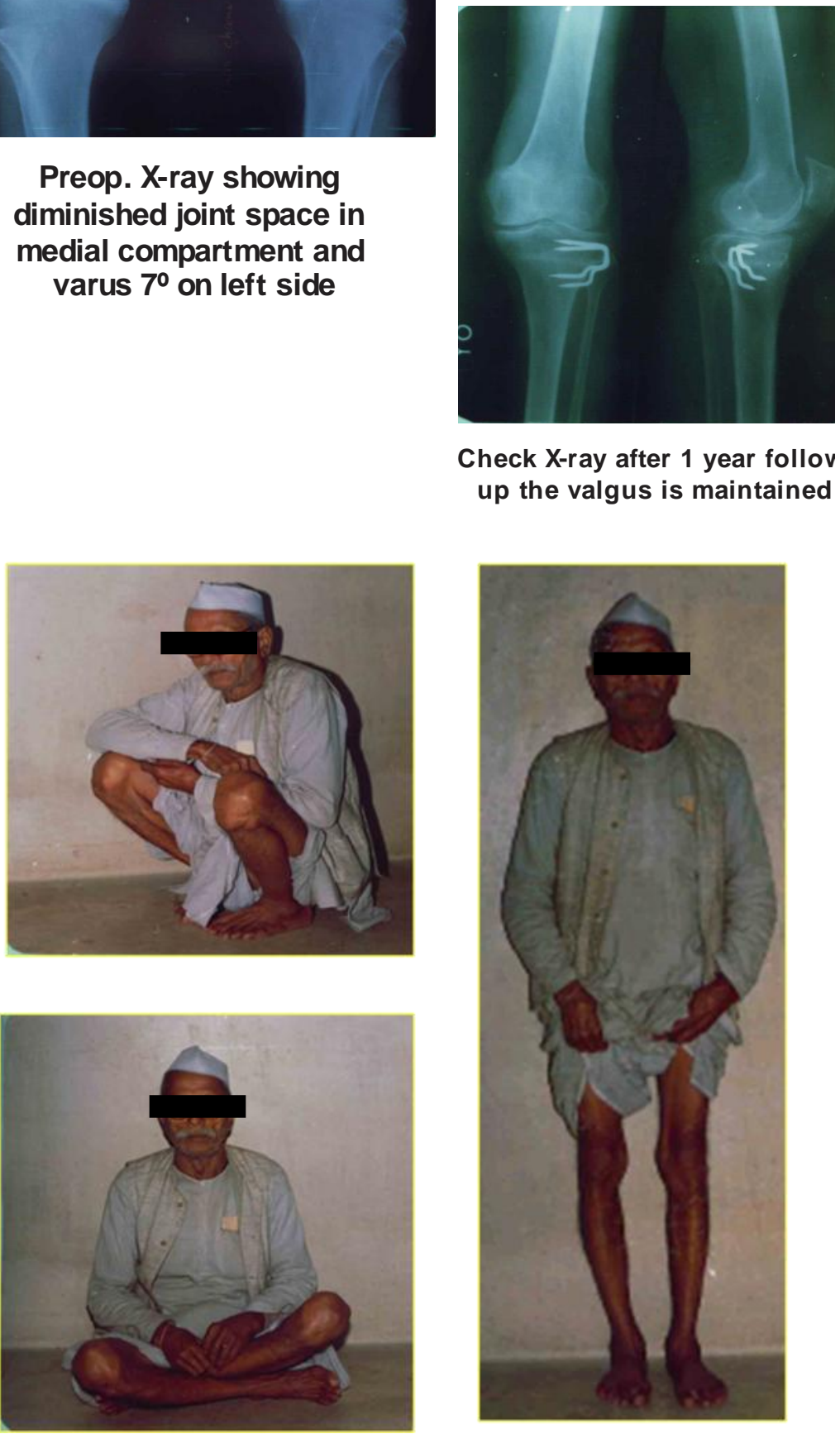

Check X-ray after 1 year follov up the valgus is maintained

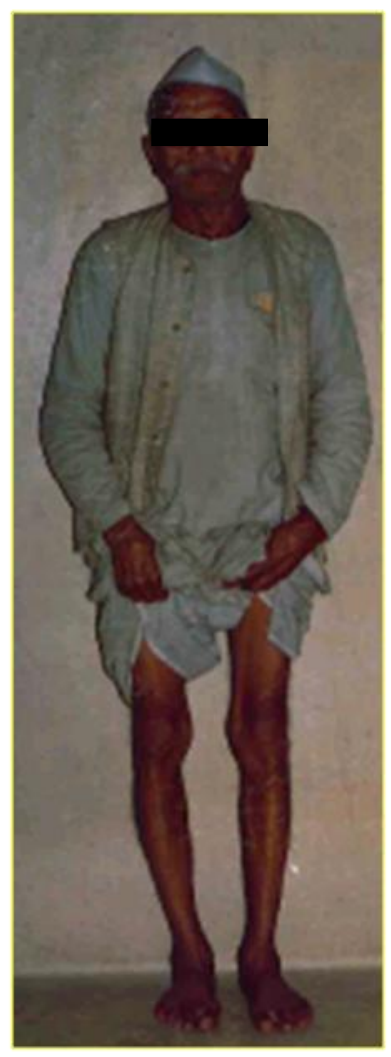

Showing functional Results 
CASE NO. 2
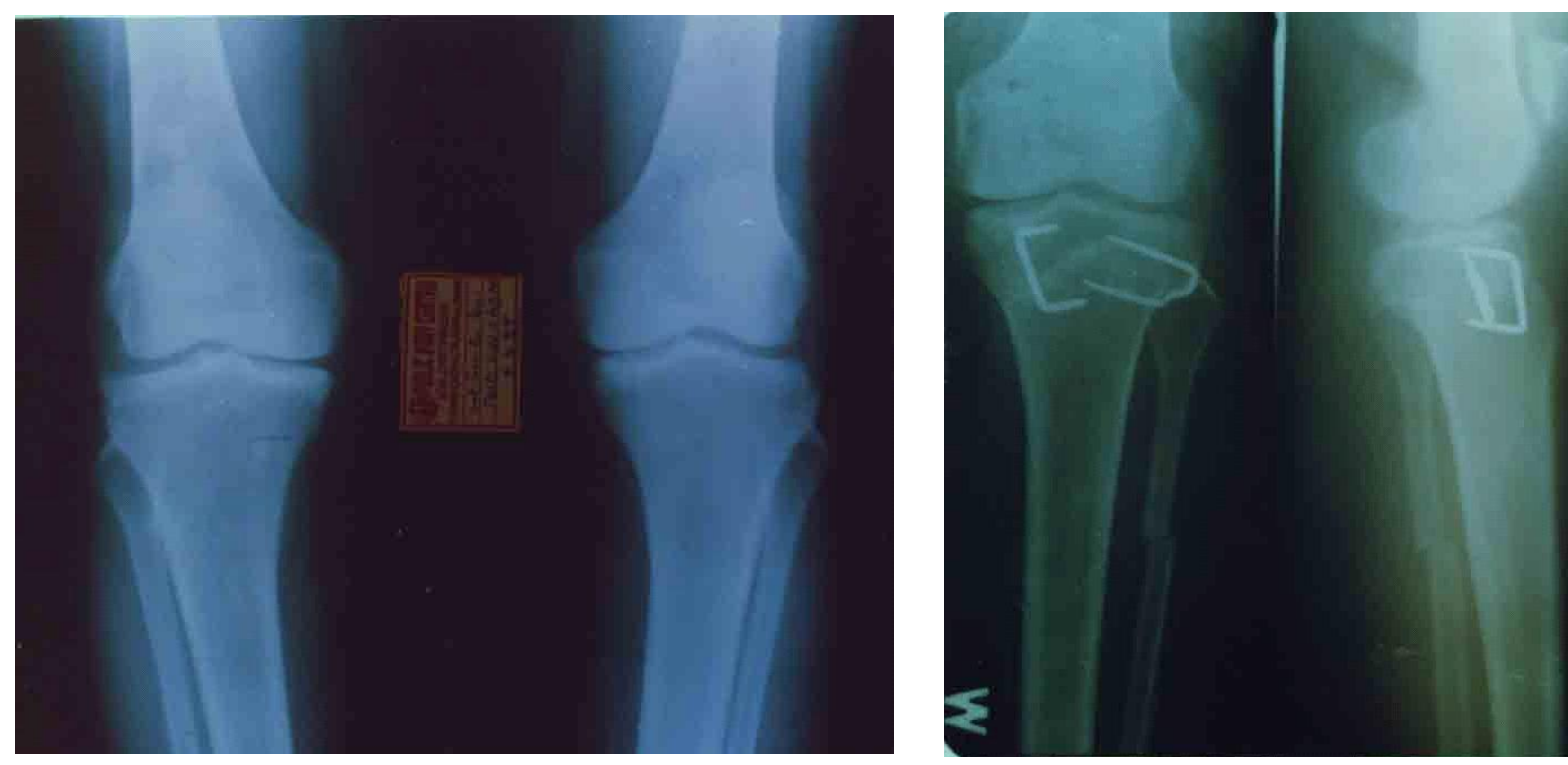

Pre-op. X-ray showing bilateral varus deformity at knee and diminished joint space on medial side.

Operated side $L$ had varus of $7^{\circ}$

Post-op. X-ray after dome osteotomy space in medial compartment has appeared the fibula is osteotomised in mid. third

CASE NO. 2

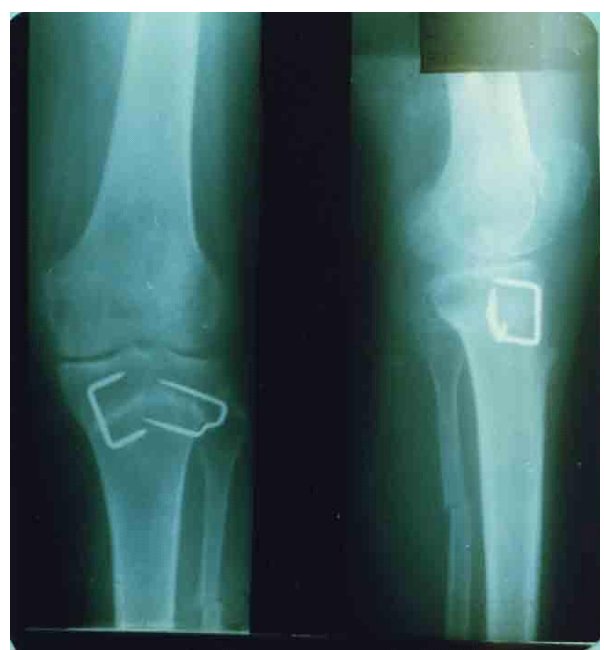

Post-op. at 3 months. Valgus is maintained. healina is in nroaress

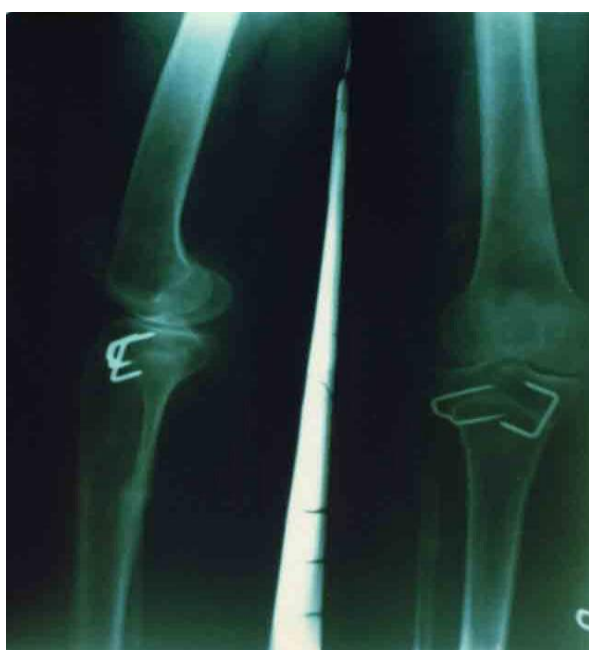

Post-op. at 9 months. Correction is maintained. osteotomv has healed 

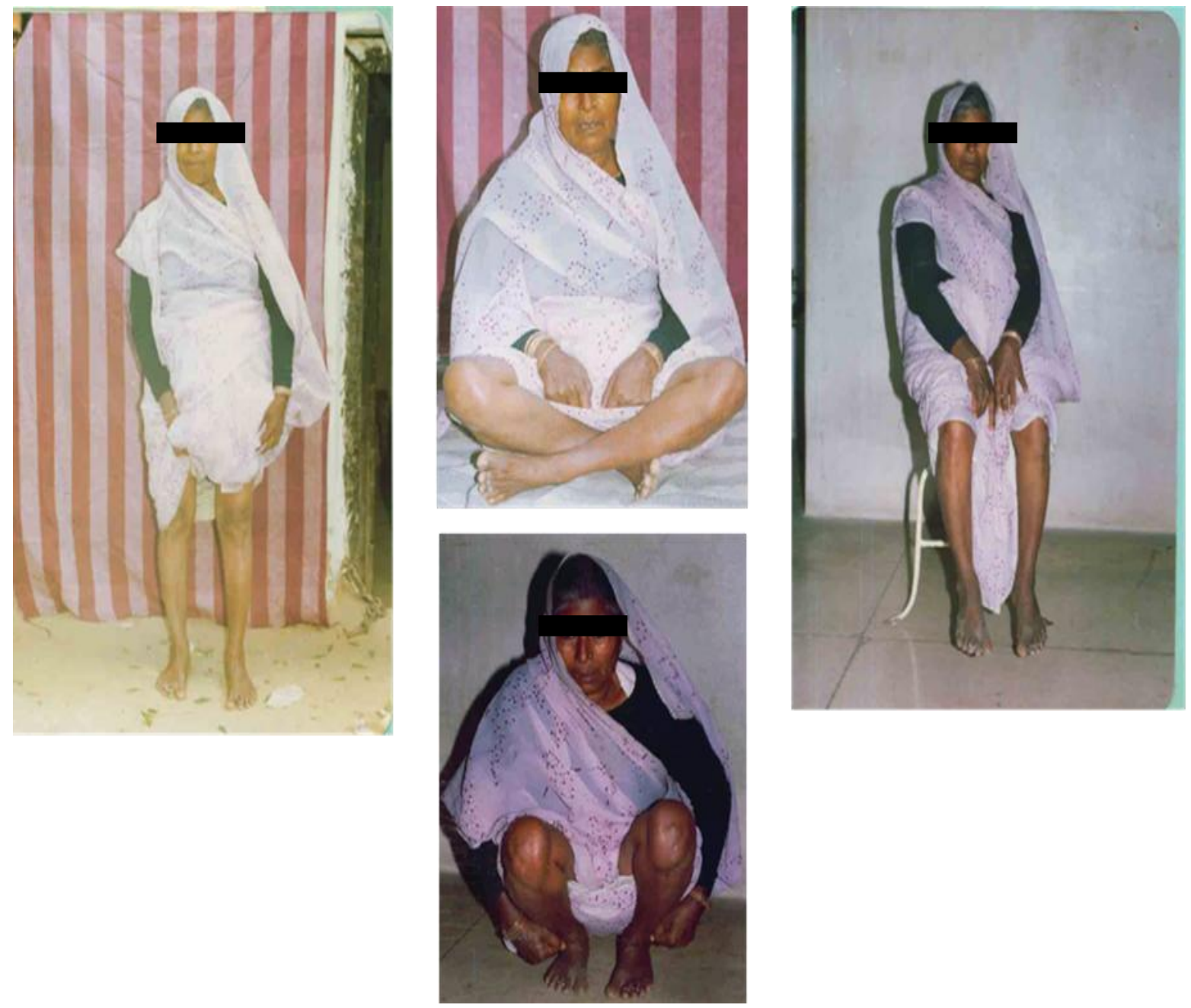

Showing functional resutls 


\section{CASE NO. 3}
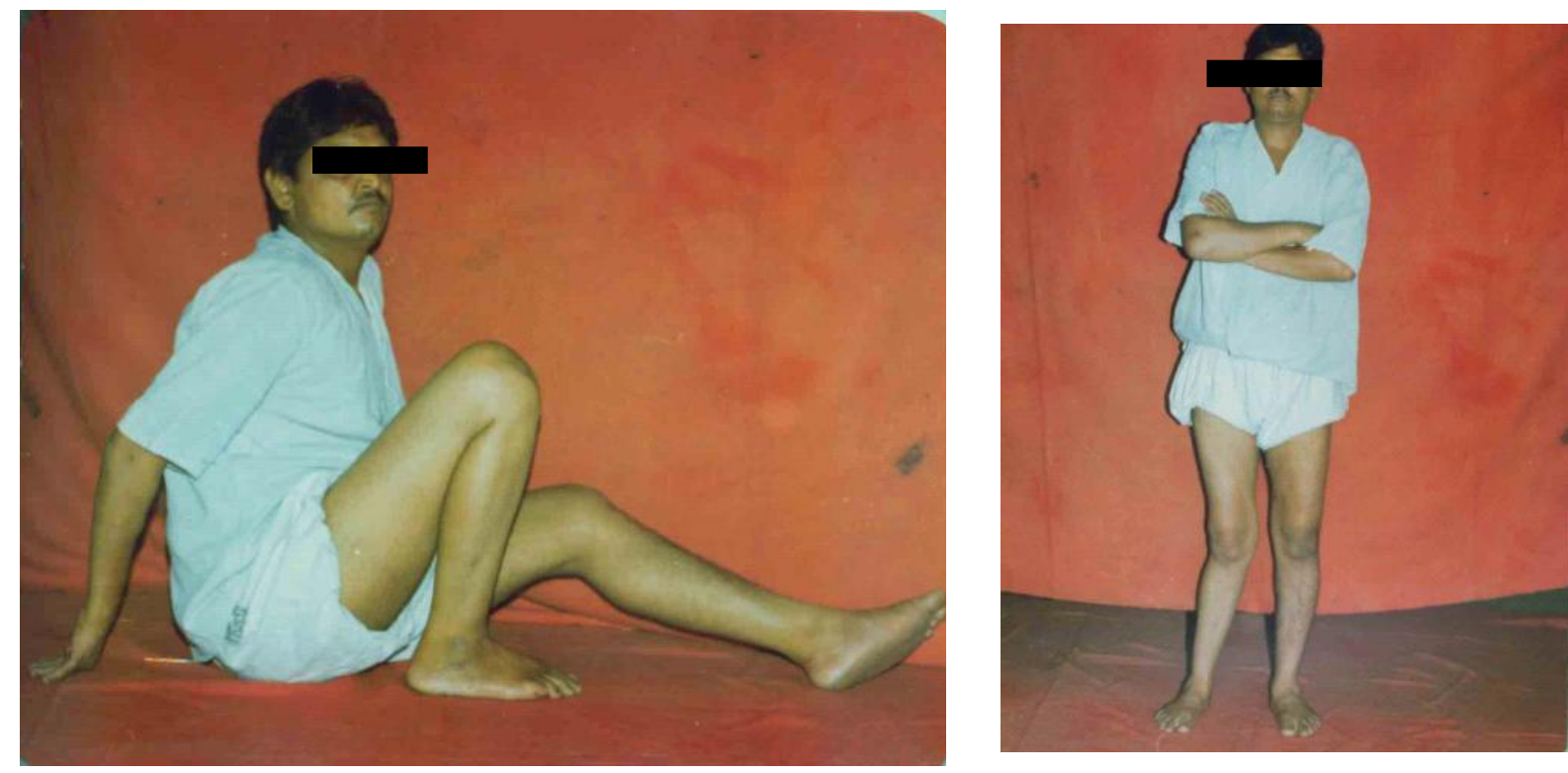

Pre-op. X-ray showing involvement of lateral compartment with $15^{\circ}$ Valgus and flexion deformity at knee

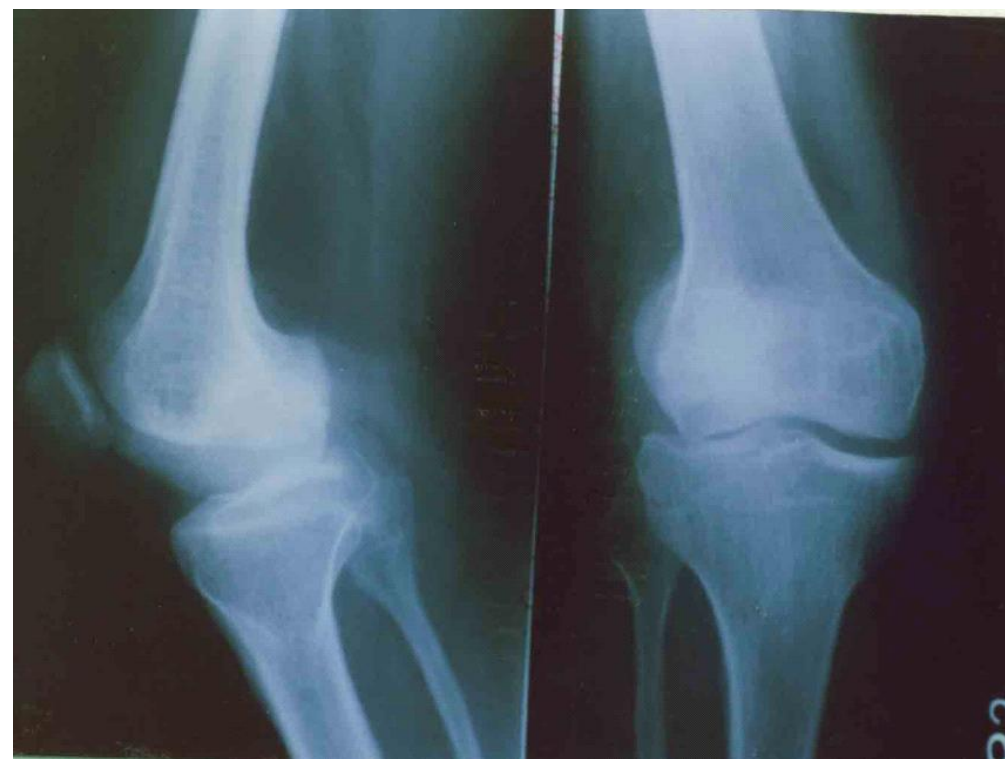

Pre-on. valaus deformitv and amount of knee flexion 


\section{CASE NO. 3}
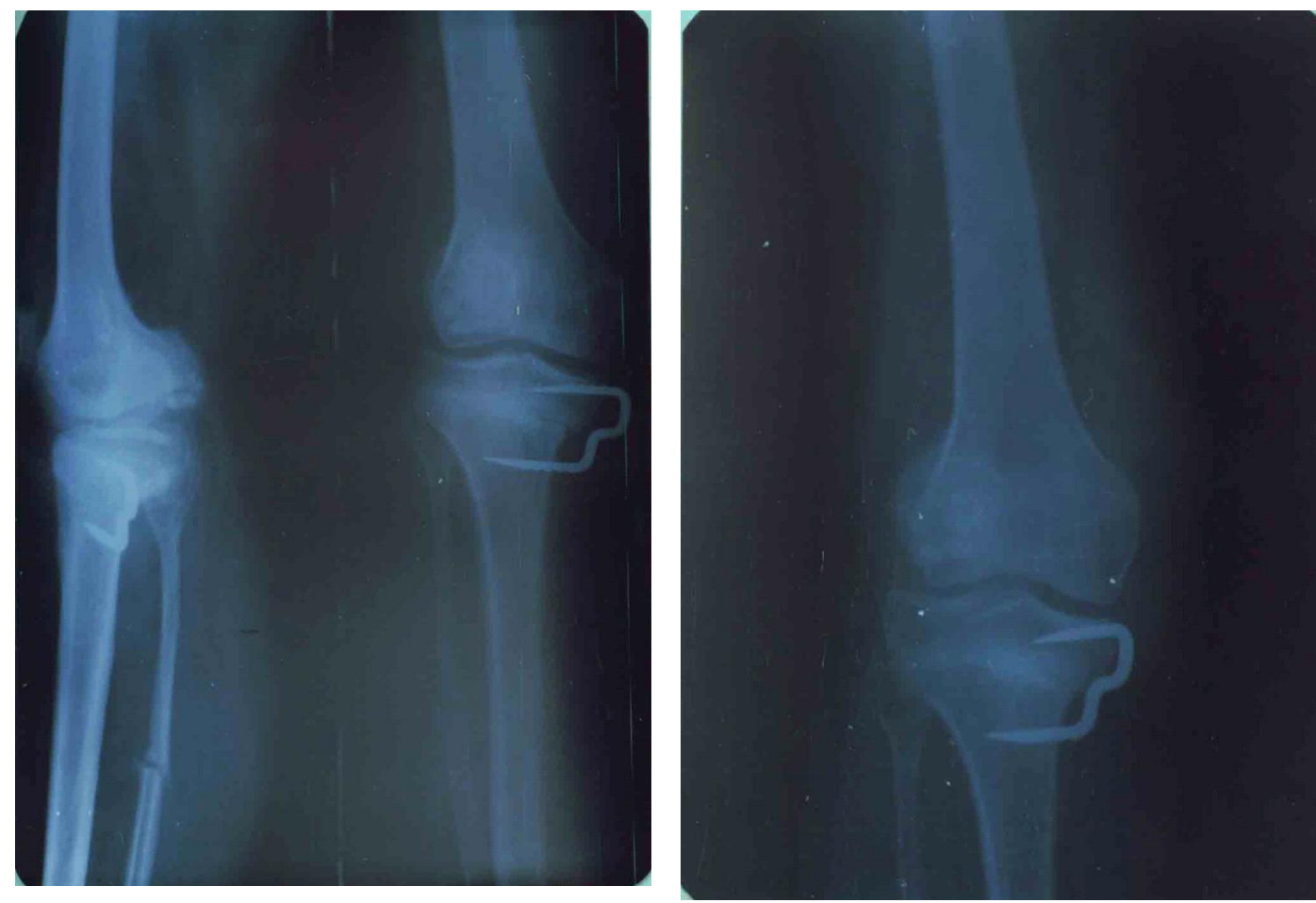

Immediate post-op. showing wedge resection from medial side and space in

the lateral compartment is created. Valqus is reduced to $6^{\circ}$

14 months follow up with maintenance of correction and healing of osteotomy
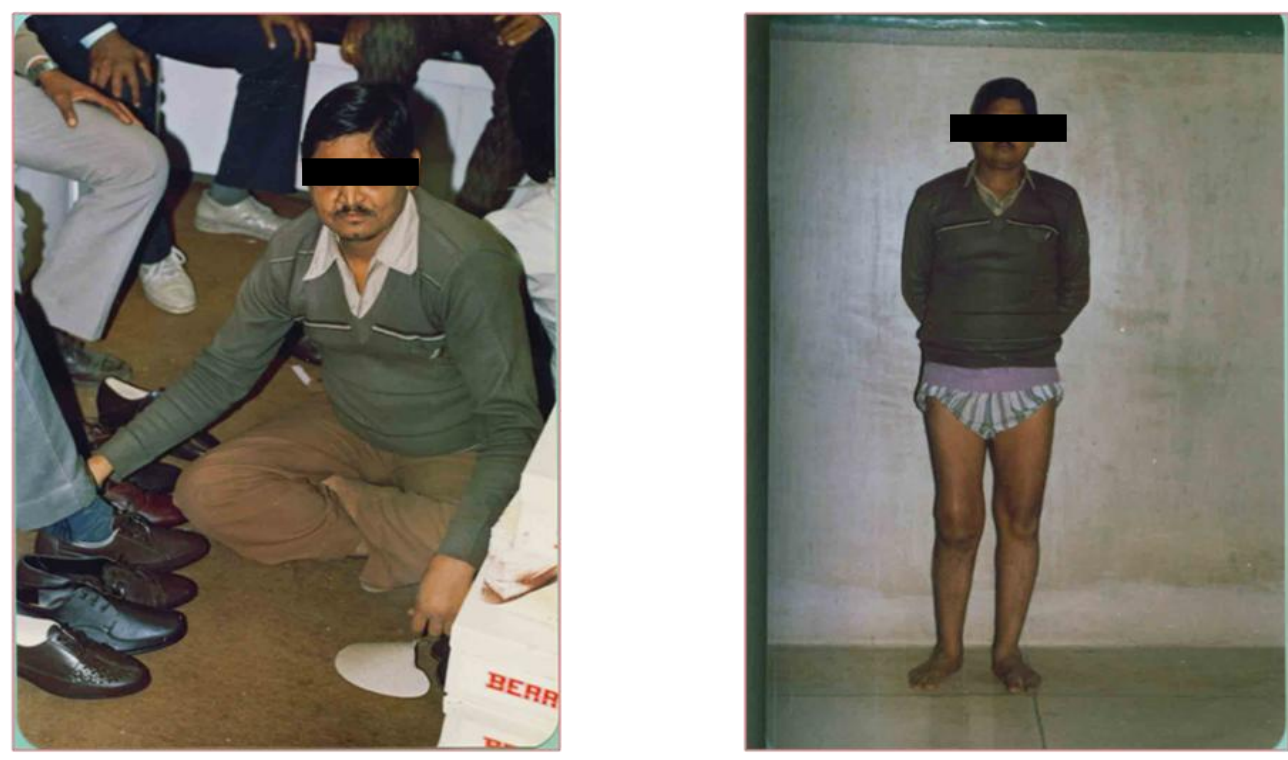

Showing post-op. corrected deformity of the limb and functional result. Post-op full flexion at knee enabled him to do his job satisfactorily 
CASE NO. 4

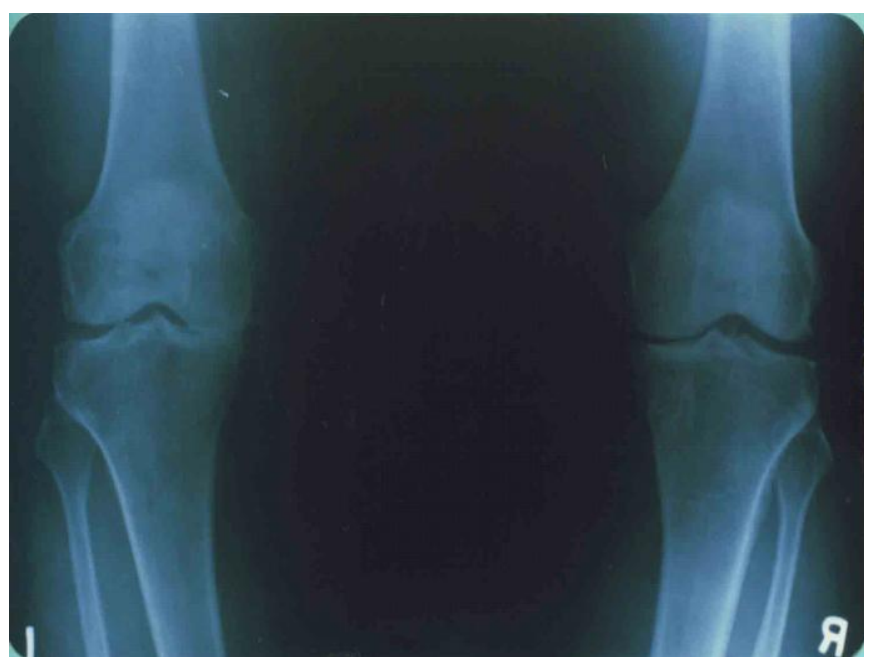

Pre-op. X-ray showing varus deformity and diminished joint space on medial side in left knee $\left(7^{\circ}\right)$

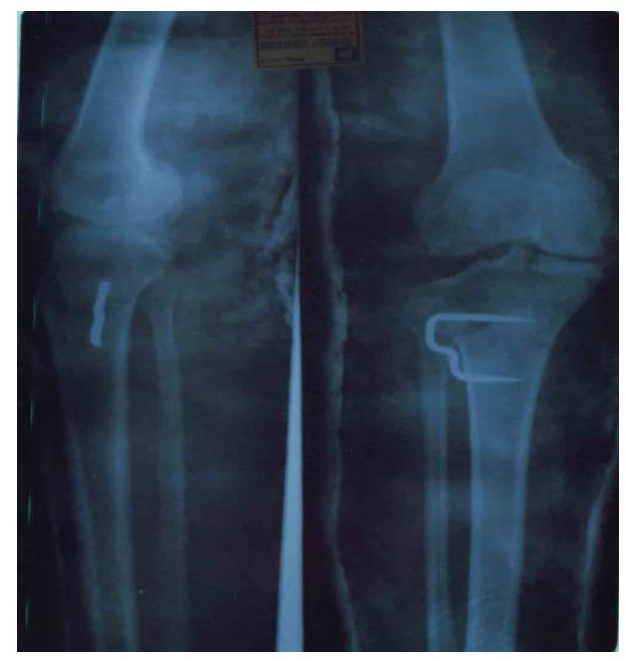

Immediate post -op. showing intra articular fracture of lateral condial of tibia. This occurred while attempting correction in wedge osteotomy

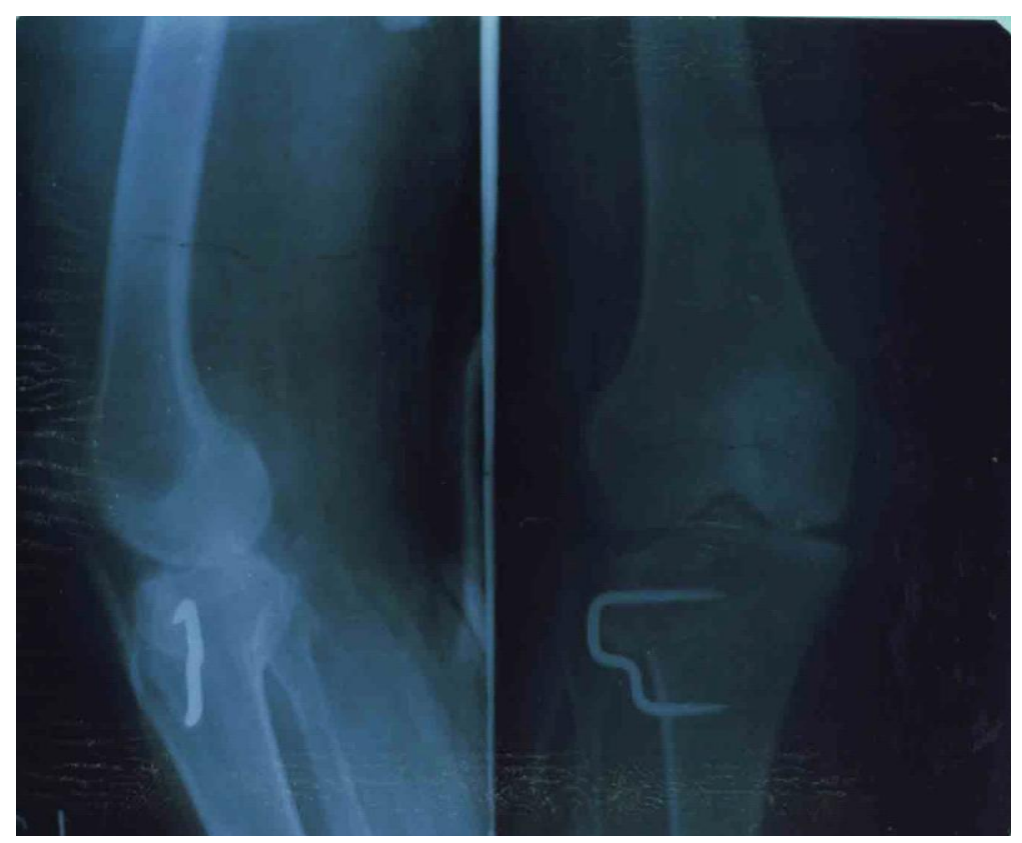

Check X -ray after 3 months showing evidence of healing. The corrected tibiofemoral alignment to valgus is mointoinnN

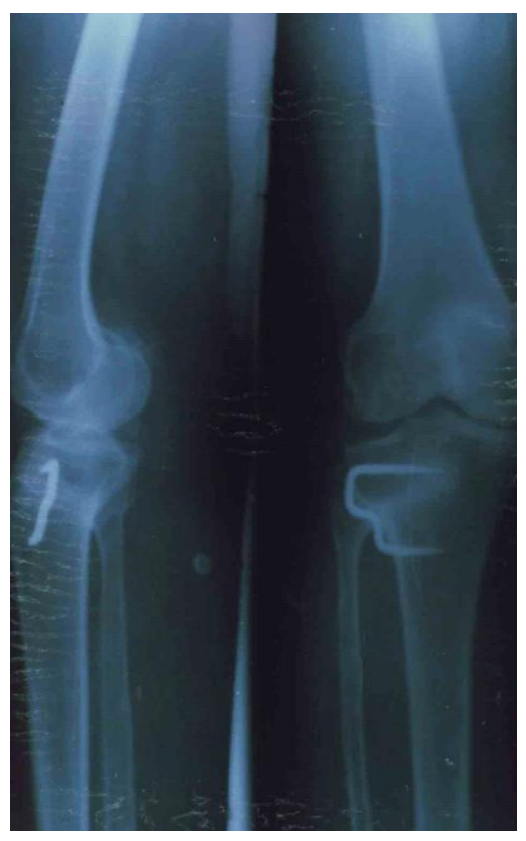

18 months follow -up fractured healed and valgus mointoinnd 
Int.J.Curr.Res.Aca.Rev.2016; 4(8): $x x-x x$

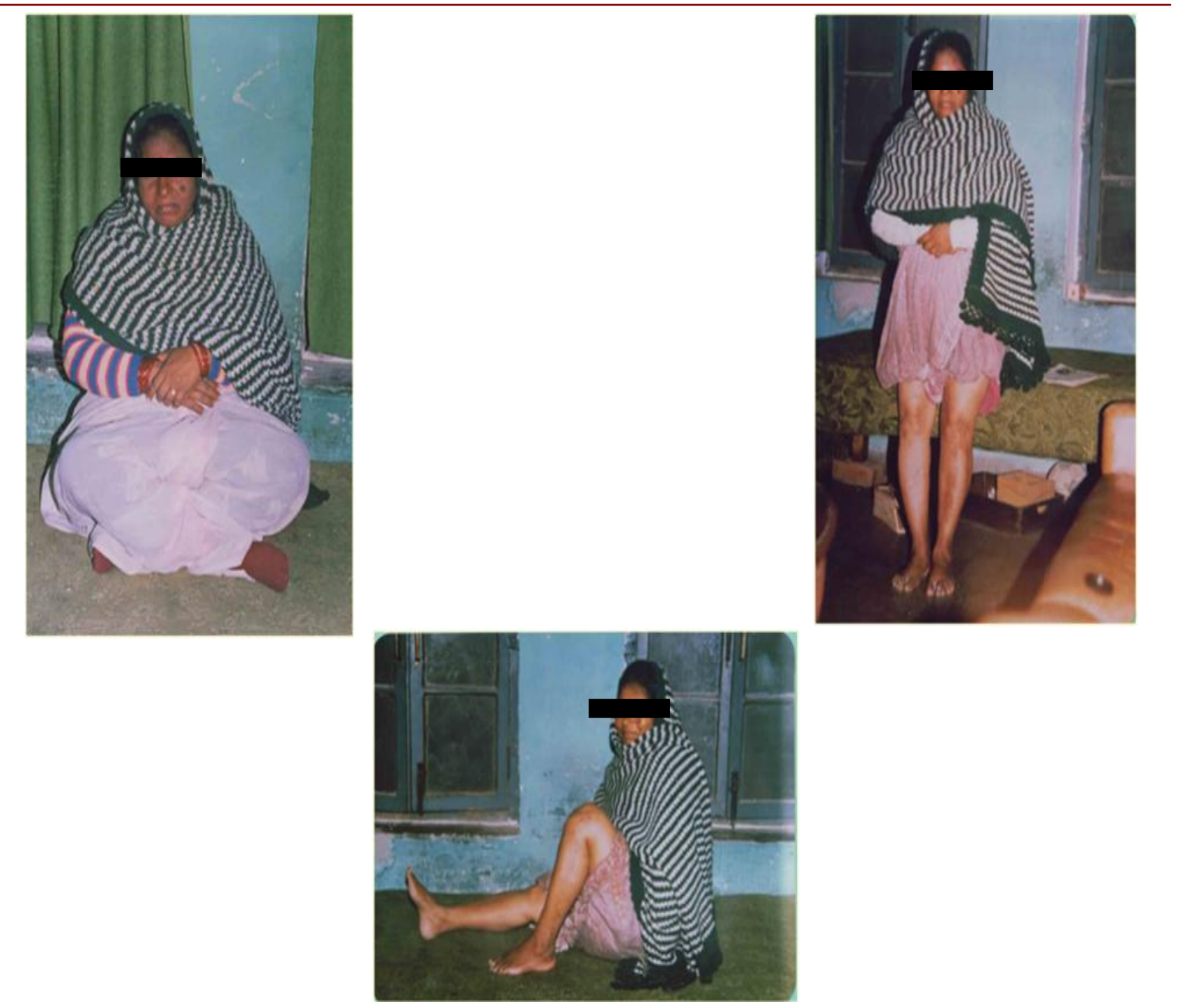

Showing functional resutls 


\section{CASE-5}
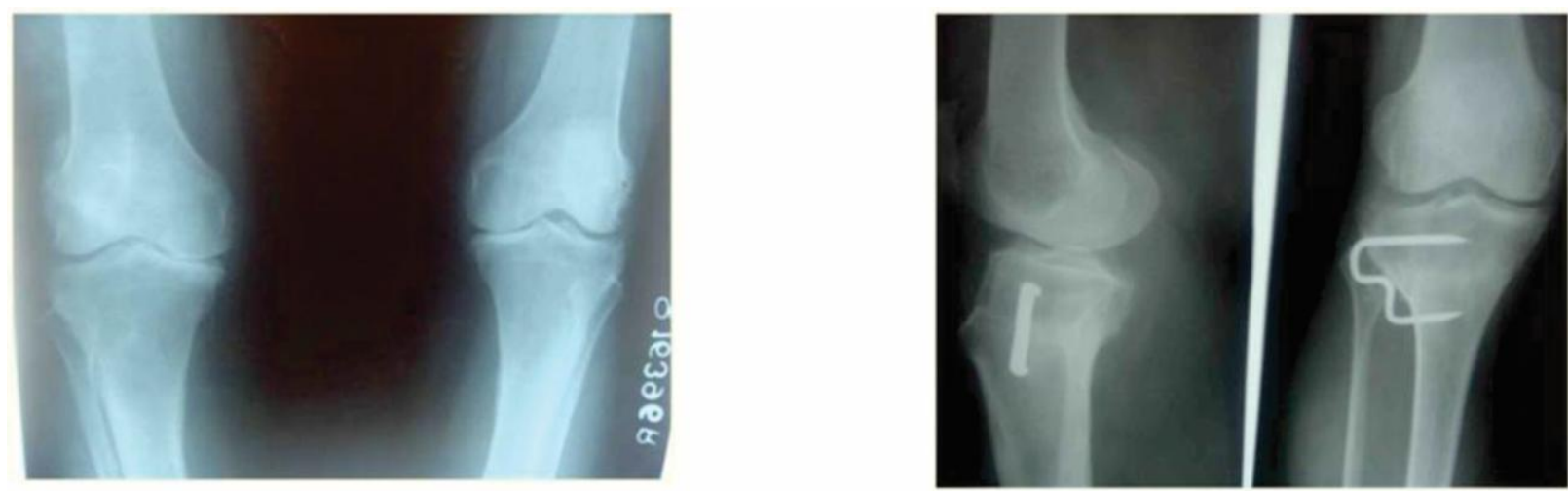

Pre.-op.

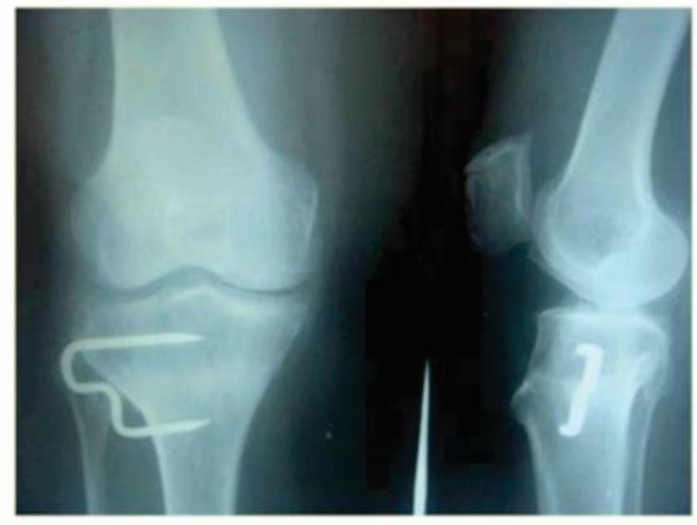

Immediate Post-op.

3 months follow-up

Valgus is maintained

\section{CASE-5}
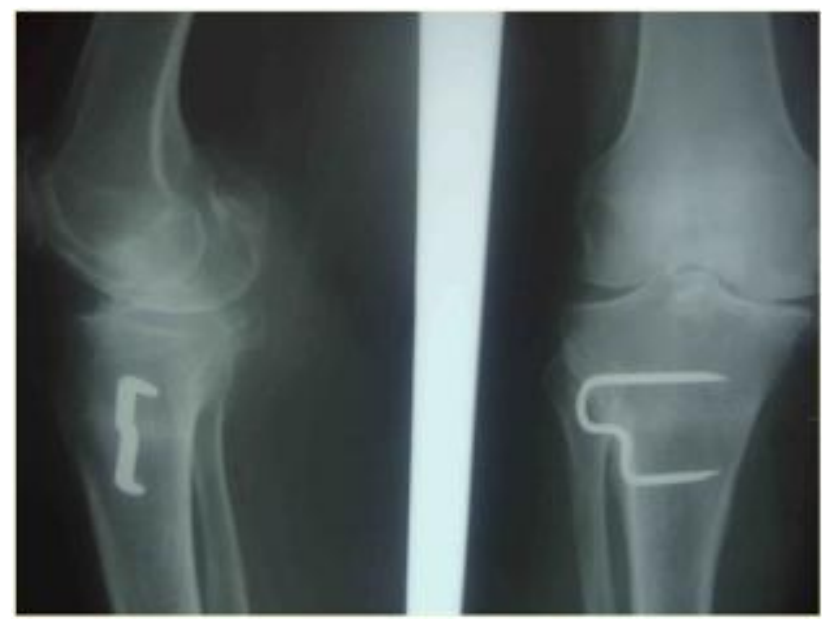

3 months follow-up
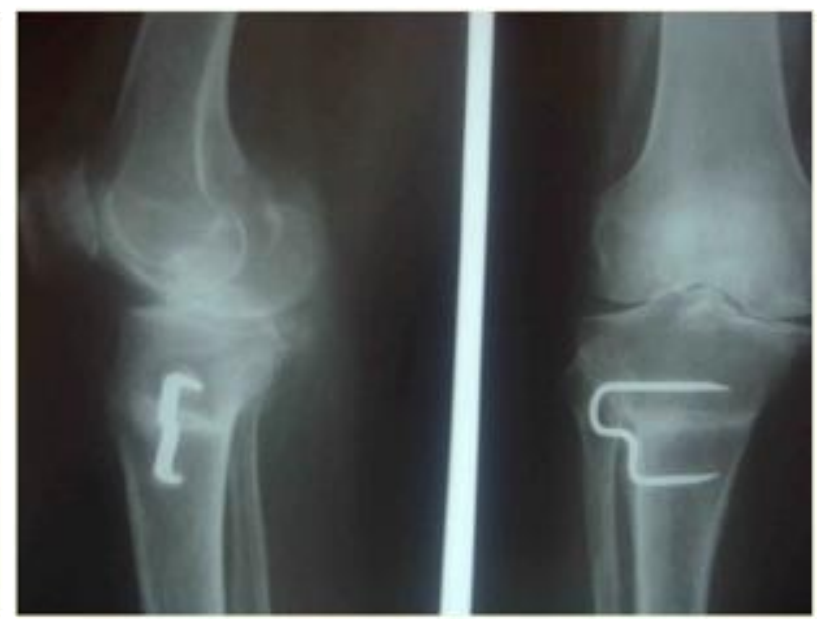

3 months follow-up 
Int.J.Curr.Res.Aca.Rev.2016; 4(8): $x x-x x$

CASE-5
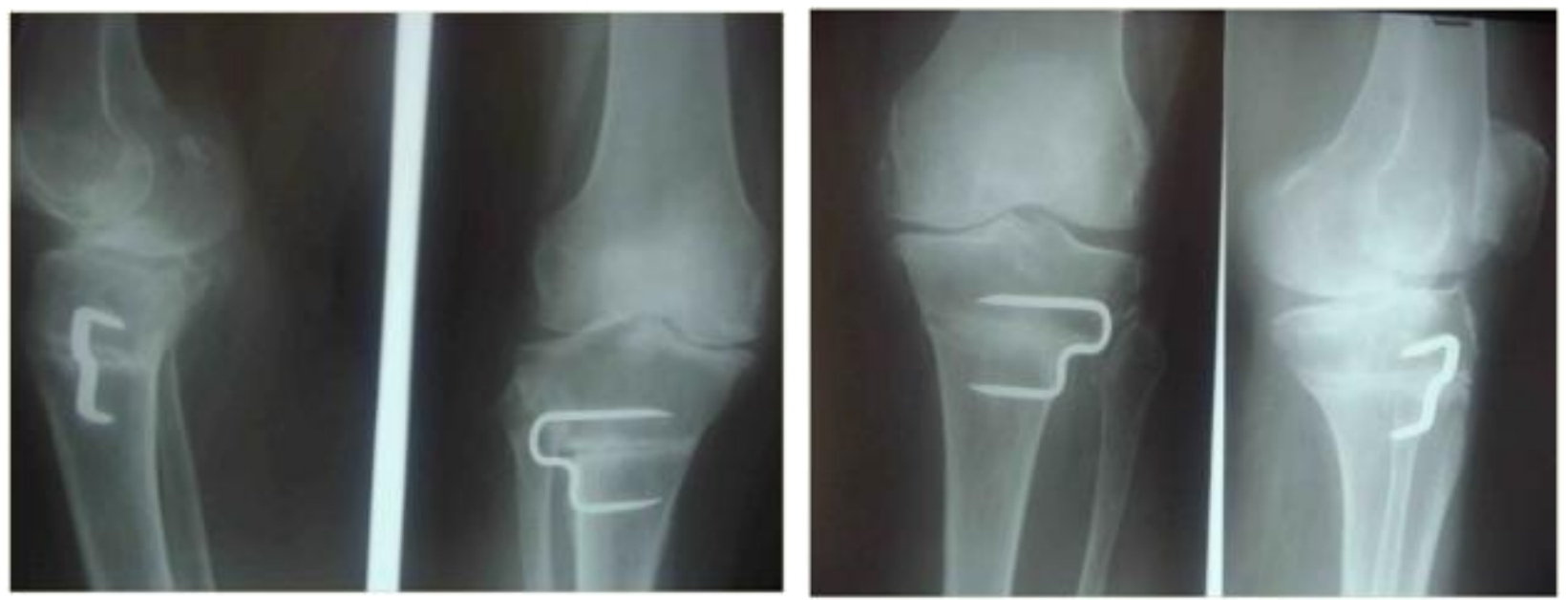

1 year follow-up

1 year follow-up

CASE-5

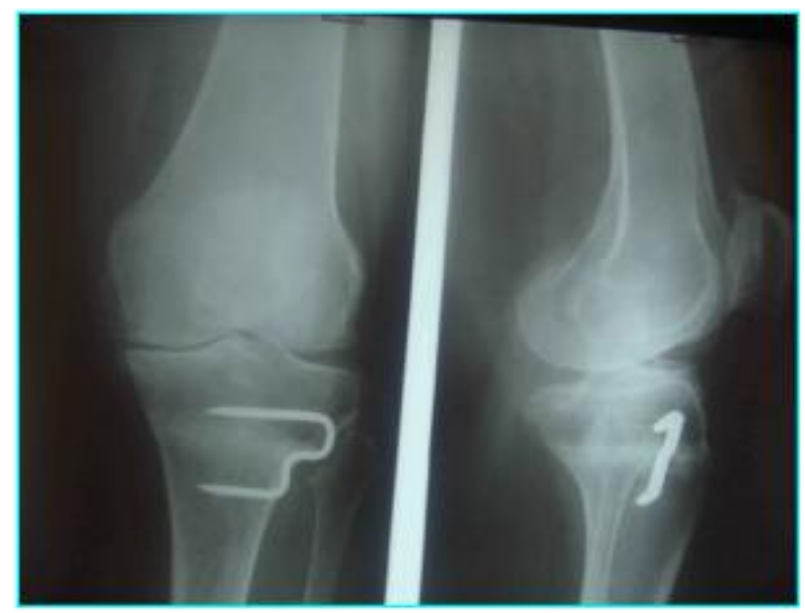

3 years follow-up

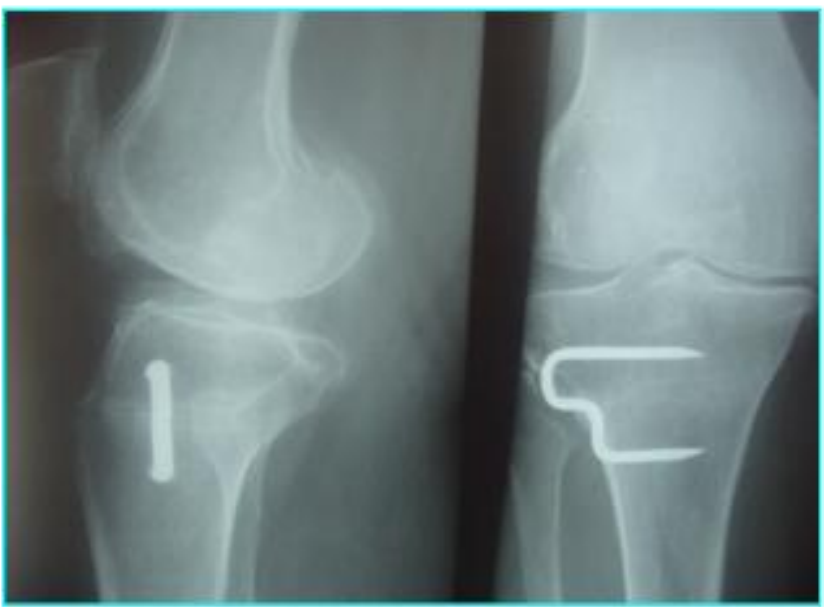

5 years follow-up 


\section{CASE-6}
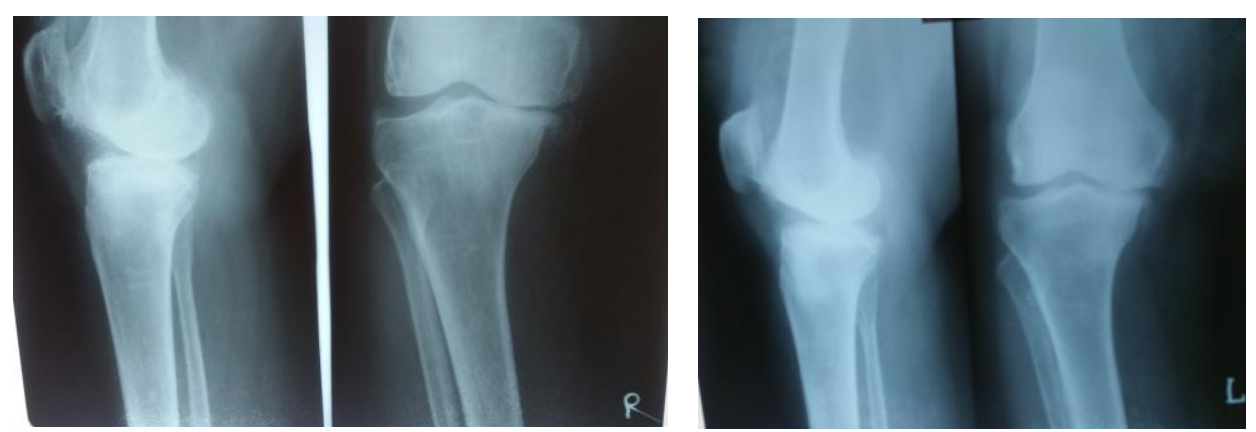

Pre-op. X-ray

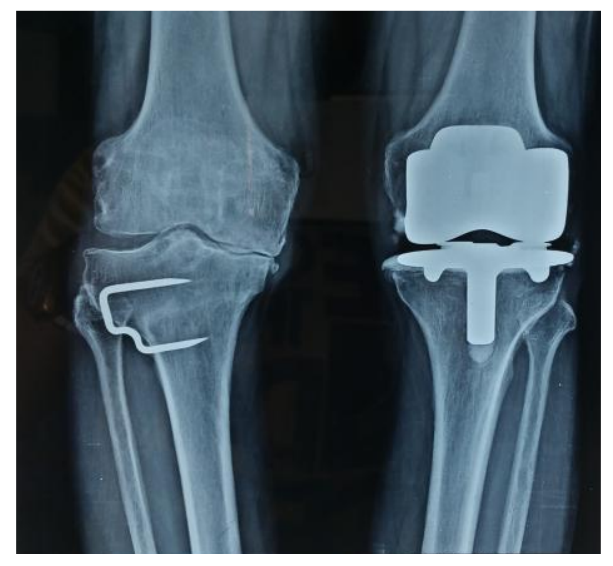

10 years follow up

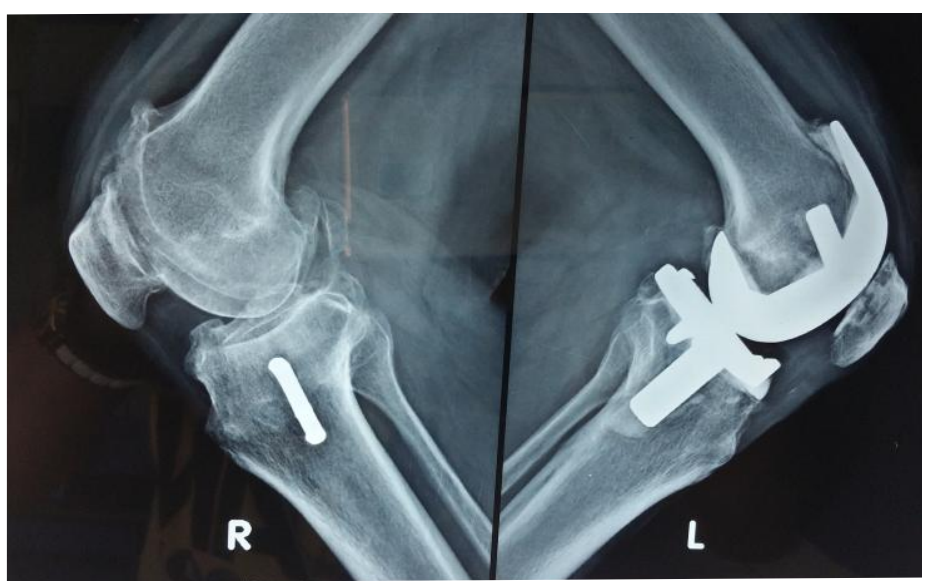

10 years follow up 
Int.J.Curr.Res.Aca.Rev.2016; 4(8): $x x-x x$

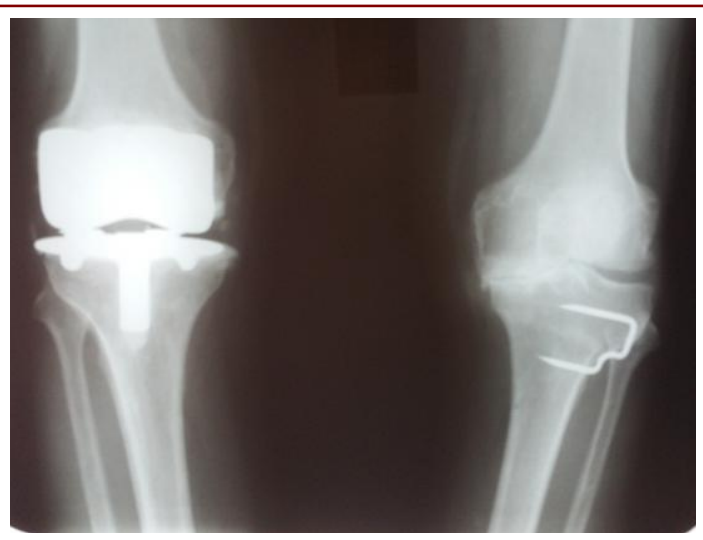

20 years follow up

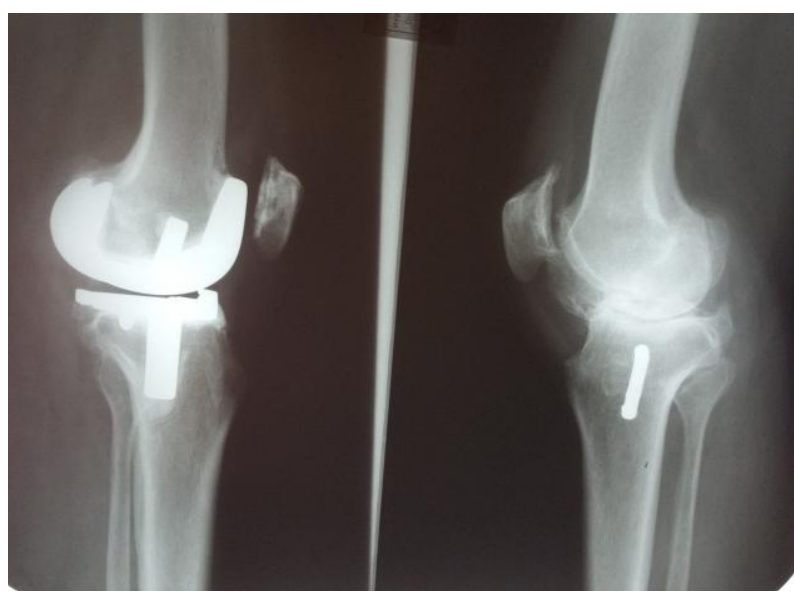

20 years follow up
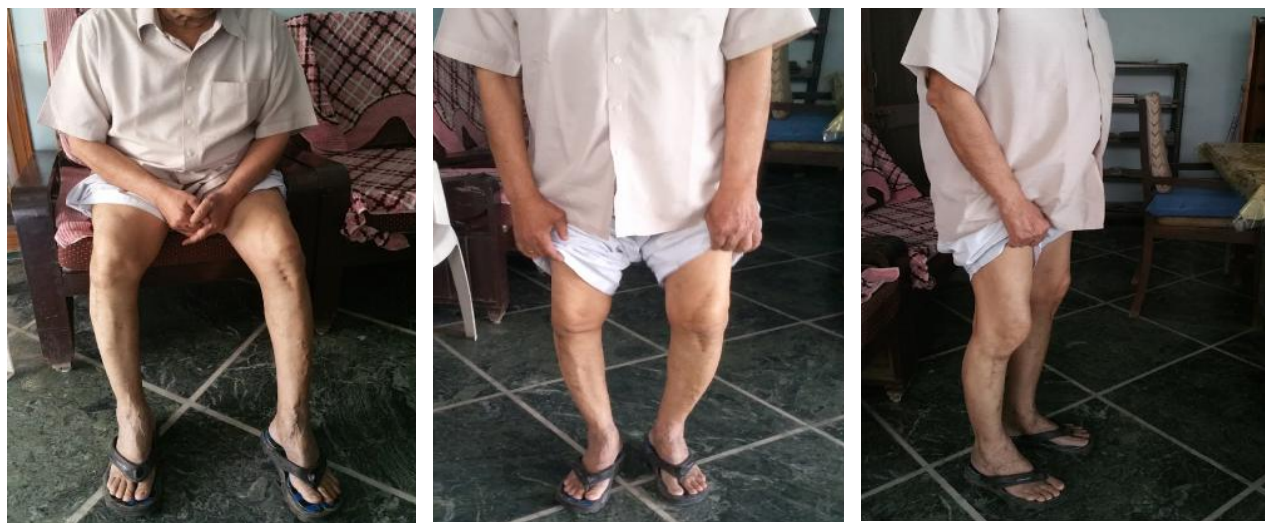

Showing the present status of the patient

Another signification observation regarding the relationship between postoperative tibiofemoral alignment and persistent pain was made. Cases with $1-10^{\circ}$ of valgus alignment $(71.5 \%)$ cases had none or mild pain only. All cases with overcorrection (6.6\%) had persisteing moderaly severe pain. This finding is same as observed by Hiromu S. and John Insall (1977) but there are many others who favoured are 
recommended overcorrection eg. P.V. Seal and R.N.W. Chan (1975) Donald B. Kettelkamp Wenger and Corolyn Thompson (1976) J.P. Blanched, Glord, JH Merotte, JL Gullams and J.P. Besse (1979) and Anthony F. Pachelli and Engene E. Kaufman (1987). There is third group of surgeons represneted by Appel H. and Friberg S (1972) who believe that "Osteotomy had a very good and long lasting effect upon pain at rest, regardless of postoperative varus or valgus angle and the effect of pain in motion is less predictable".

In present sereis, results of wedge and dome osteotomies were compared. It was found that dome osteotomy gives better results as comapred to wedge osteotomy and wedge osteotomy at the level of tibial tuberosity give better results than wedge osteotomy below the level of tibial tuberosity (Sarkin, 1972).

Painless knees following dome osteotomy resutled in $43.7 \%$ cases as comapred to $38.4 \%$ cases of wedge osteotomy. Knee flexion of more than $120^{\circ}$ was obtained in $43.7 \%$ caes of dome osteotomy as comaprd to $34.6 \%$ cases of wedge osteotomy. $37.5 \%$ cases of dome osteotomy could walk out doors for unlimited distances as comapred to $30.7 \%$ cases of wedge osteotomy.

$43.7 \%$ cases of dome osteotomy could squat easily compared to $34.6 \%$ cases of wedge osteotomy. Similarly $50 \%$ cases of dome osteotomy were able to sit crosslegged as comapred to $346 \%$ cases of wedge osteotomy.

The above comparison proves that dome osteotomy gave better functional resutls as comapred wedge osteotomy in this series. It is important to note there was weakness of dorsiflexion of foot and pain at site of fibular osteotomy which was due to fibular osteotomy in mid shaft. It seems that few nerve fibres to extensor Hallucis and Ext. dig. Longus are injured during fibrular osteotomy and they are responsible for weakness of dorsiflexion of foot or the great toe only (Table-17).

Intraarituclar fracture was noted in 8 cases of wedge osteotomy all these had preoperative genu varum deformity. While osteotomising through the upper tibia and removing the wedge, medial cortex was undevided and correction was attempted in this position which led to the fracture of tibial condyle. In these cases plaster immobilization was done till there was radiological evidence of union.

\section{Conclusion}

In our study it was seen that all patients were benefited by surgery as regards the relief of pain. Very old and obese patients showed poor results after surgery due to their inability to do required physiotherapy. Patients having symptoms for shorter duration and showing early evidence of radiological changes responded to surgery better as compared to those having advanced changes. Patient with 1-10 of postoperative valgus in tibio-femoral alignment obtained maximum pain relief and good range of motion. Over correction and failure to achieve valgus showed poor results. $75 \%$ of patients showed good results, $20 \%$ fair \& $5 \%$ poor. Better resutls were obtained by dome osteotomy as compared to wedge osteotomy regarding relief of pain, post oerpative range of knee motion, and abilities to walk distances, climb the stairs, squat or sit crosslegged. Osteotomy of fibula in dome osteotomy required special care to avoid complications like pain at fibular osteotomy site and weakness of dorsiflexion of foot. Thus high tibial osteotomy is a boon for early osteoarthritis of knee with 
Int.J.Curr.Res.Aca.Rev.2016; 4(8): $x x-x x$

unicompartmental involvement and to some extent with moderate to advance osteoarthritis in developing countries as clearly indicated in our study.

\section{References}

Ackroya, C.E., Poloyzoides, A.J. 1977. Patellectomy for Osteoarthritis., Jr. Bone \& Joint Surg., 58-B; 108.

Benjamin, A. 1969. \$ Double osteotomy for painful knee in rheumatoid arthritis and osteoarthritis. Jr. Bone \& Joint Surg., 51B: 69.

Berkeiser, E.J. 1939. Sccision of patella in arthritis of knee joint. J.A.MA. 111s 2303.

Coventry, M.B. 1973. Osteotomy about knee for degenerative and rheumatoid arthritis. $J r$. Bone \& Joint Surg.,55-A; 23.

Coventry, M.B. 1969. Stepped staple for upper tibial osteotomy. Jr.Bone \& Joint Surg. $J 1-A$; 101B.

Coventry, M.B. 1987. Proximal tibial varus osteotomy osteoarthritis of the lateral compartment of the knee. Jr. Bone \& Joint Surg., 69-A; 32.

David, L., Macintosh \& R. Peter Welsh. 1977. Joint debri-dement: Complement to high tibial osteotomy in treatment of degenerative arthritis of the knee. Jr. Bone \& Joint Surg., 59-A; 109.

Dugdale, T.W., Noyes, F.R., Styer, D. 1992. Preoperative planning for high tibial osteotomy. The effect of lateral tibiofemoral separation and tibiofemoral length. Clin. Orthop. Relat. Res., (274): 248-264.

Fujisawa, Y., Masuhara, K., Shiomi, S. 1979. The effect of high tibial osteotomy on osteoarthritis of the knee An arthroscopic study of 54 knee joints. Orthop. Clin. North Am., 10: 585-608.
Insall, J.N., Joseph, D.M., Msika, C. 1984. High tibial osteotomy for $\mathrm{v}$ arus gonathrosis. A long-term follow-up study. J. Bone Joint Surg Am., 66: 1040-1048.

Jakob, R.P., Jacobi, M. 2004. Closing wedge osteotomy of the tibial head in treatment of single compartment arthrosis. Orthopade, 33: 143-152.

MacIntosh, D.L., Welsh, R.P. 1977. Joint debridement-a complement to high tibial osteotomy in the treatment of degenerative arthritis of the knee. J. Bone Joint Surg. Am., 59:1094-1097.

Myrnerts Rune. 1980. Optimal correction in high tibial osteotomy for varus deformity., Acta.Orthop. Scand., 515- 689.

Sarkin, T.L. 1972. Indications for intra-articular steroid in osteoarthritis of the knee, South African M.J., *f6; 157.

Song, E.K., Seon, J.K., Park, S.J., Jeong, M.S. 2010. The complications of high tibial osteotomy: closing- versus openingwedge methods. J. Bone Joint Surg. Br., 92: $1245-1252$.

Steindler, A. 1955. Synovectomy and fat pad removal in knee joint., Jr. Bone \& Joint Surg., 37-B; 392.

Sundaram, N.A., Hallett, J.P. \& Sullivan, M.F. 1986. Dome osteotonjy of the tibia for osteoarthritis of the knee, Jr. Bone \& Joint Surg., 68-B; 782.

van Raaij, T.M., Reijman, M., Furlan, A.D., Verhaar, J.A. 2009. Total knee arthroplasty after high tibial osteotomy A systematic review. BMC Musculoskelet Disord., 10: 88.

Wynn Jones, C.H., Ansell, B.M. and Arden, G.P. 1979. A prospective study of Benjamin double osteotomy of the knee in rheumatoid arthritis and osteoarthritis, $J r$. Bone \& Joint Surg., 61-B; 121.

\section{How to cite this article:}

Amit Agarwal, Imran Sajid, Anubhav Agarwal, Harish Chandra. 2016. High Tibial Osteotomy: Long Term Follow-Up. Int.J.Curr.Res.Aca.Rev.4(8): 131-157.

doi: http://dx.doi.org/10.20546/ijcrar.2016.408.012 